University of Louisville

ThinkIR: The University of Louisville's Institutional Repository

Electronic Theses and Dissertations

$8-2020$

\title{
Connecting right-wing authoritarianism to environmental beliefs and behaviors: a pilot study.
}

Rebecca Halpryn

University of Louisville

Follow this and additional works at: https://ir.library.louisville.edu/etd

Part of the Other Sociology Commons

\section{Recommended Citation}

Halpryn, Rebecca, "Connecting right-wing authoritarianism to environmental beliefs and behaviors: a pilot study." (2020). Electronic Theses and Dissertations. Paper 3489.

https://doi.org/10.18297/etd/3489

This Master's Thesis is brought to you for free and open access by ThinkIR: The University of Louisville's Institutional Repository. It has been accepted for inclusion in Electronic Theses and Dissertations by an authorized administrator of ThinkIR: The University of Louisville's Institutional Repository. This title appears here courtesy of the author, who has retained all other copyrights. For more information, please contact thinkir@louisville.edu. 
CONNECTING RIGHT-WING AUTHORITARIANISM TO ENVIRONMENTAL BELIEFS AND BEHAVIORS: A PILOT STUDY

\author{
By \\ Rebecca Halpryn \\ B.A., Berea College 2018
}

\begin{abstract}
A Thesis
Submitted to the Faculty of the

College of Arts and Sciences of the University of Louisville

In Partial Fulfillment of the Requirements

for the Degree of
\end{abstract}

Master of Arts

in Sociology

\author{
Department of Sociology \\ University of Louisville \\ Louisville, Kentucky
}

August 2020 

CONNECTING RIGHT-WING AUTHORITARIANISM TO ENVIRONMENTAL BELIEFS AND BEHAVIORS: A PILOT STUDY

\section{By}

Rebecca Halpryn

B.A., Berea College 2018

A Thesis Approved on

July 2, 2020

by the following Thesis Committee:

\begin{tabular}{c}
\hline Thesis Chair \\
Dr. Mark Austin \\
\hline Dr. Robert Carini \\
\hline
\end{tabular}

Dr. Lauren Heberle 


\section{ABSTRACT \\ CONNECTING RIGHT-WING AUTHORITARIANISM TO ENVIRONMENTAL BELIEFS AND BEHAVIORS: A PILOT STUDY \\ Rebecca Halpryn}

July 2,2020

Climate change is an urgent situation that may be alleviated by a dramatic transformation in individual's lifestyles. Right-wing authoritarianism relates to a wide variety of beliefs and behaviors, yet little is known about its relationship with environmental beliefs and behaviors. An online survey utilizing the 18 -item ACT scale, the revised NEP scale, the PEB scale, and background questions as conducted; 60 college students enrolled in introductory sociology courses responded. Multiple regression and backwards stepwise statistical methods were employed on the survey data to investigate the relationship between right-wing authoritarianism and pro-environmental beliefs and the relationship between right-wing authoritarianism and pro-environmental behaviors. Results indicate that right-wing authoritarianism and traditionalism are significantly negatively related to pro-environmental beliefs, and right-wing authoritarianism, authoritarianism, conservatism, and traditionalism are all significantly negatively related to pro-environmental behaviors. These findings will inform the researcher's hypotheses in a replicated study utilizing a larger sample size. 


\section{TABLE OF CONTENTS}

PAGE

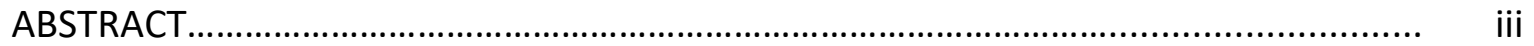

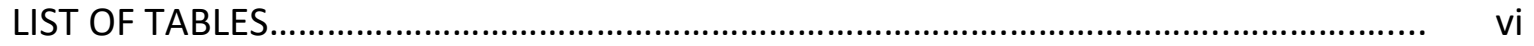

INTRODUCTION

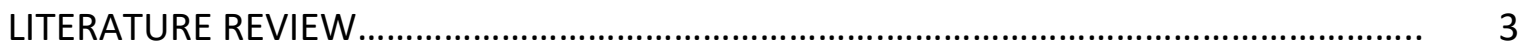

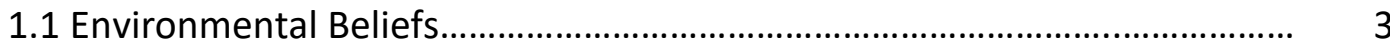

1.2 Environmental Behaviors............................................................................ 7

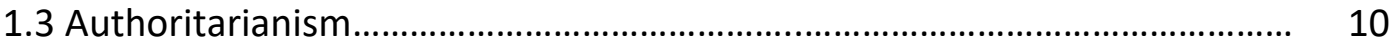

1.4 Right-Wing Authoritarianism, Environmental Beliefs,

and Environmental Behaviors....................................................................... 24

1.5 Research Aims of the Current Study.......................................................... 28

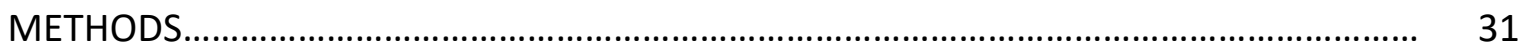

2.1 Participants and Data Collection Procedures............................................... 31

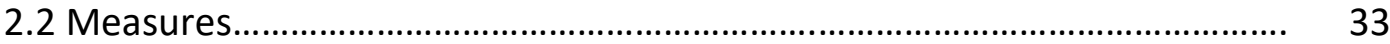

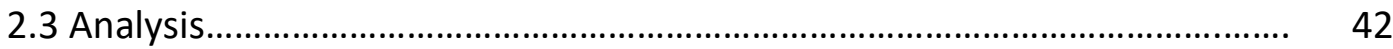

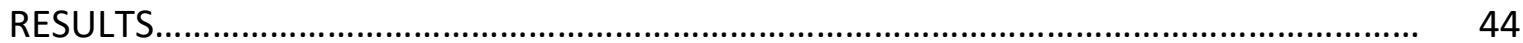

3.1 Environmental Beliefs.............................................................................. 46

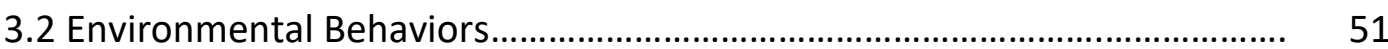




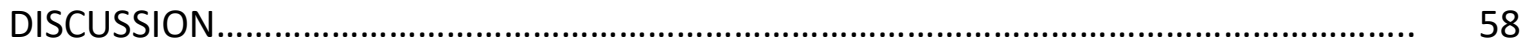

4.1 Environmental Beliefs....................................................................... 60

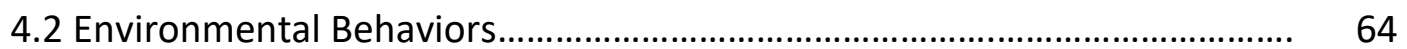

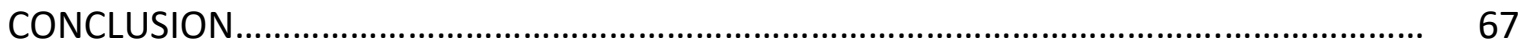

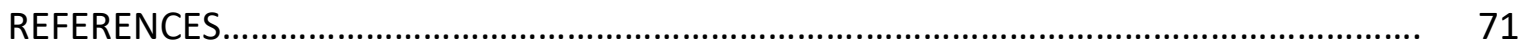

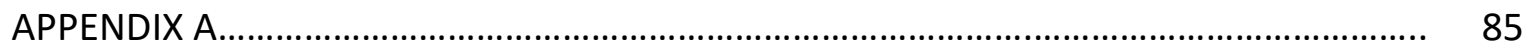

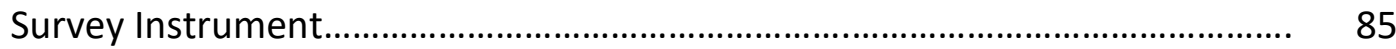

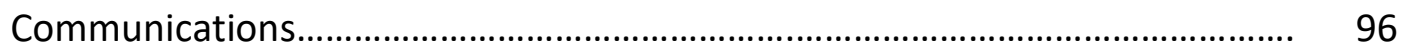

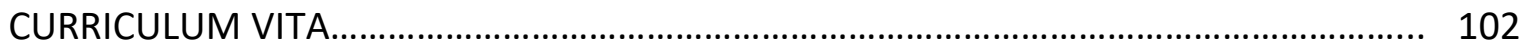




\section{LIST OF TABLES}

TABLE

PAGE

1: Descriptive Statistics for Dependent Variables .......................................... 38

2: Descriptive Statistics for Key Independent Variables.......................................... 39

3: Descriptive Statistics for Background Variables................................................... 42

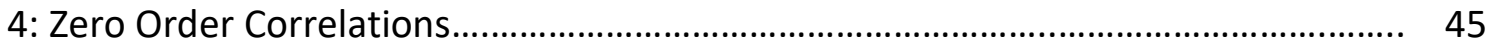

5: Multiple regression stepwise models predicting NEP scale score .......................... 48

6: Multiple regression stepwise models predicting PEB scale score........................... 52 


\section{INTRODUCTION}

Climate change is one of the most pressing issues humanity currently faces.

Despite the fact that the scientific consensus has determined that climate change is a very real and drastic threat to humanity, many people still do not believe that climate change is real or human-caused (Bain, Hornsey, Bongiorno, \& Jeffries, 2012). In November, 2019, Yale's Program on Climate Change Communication found that about one in eight Americans do not believe global warming is occurring, and about three in ten Americans who do believe it is occurring believe that it is occurring due to mostly natural causes as opposed to anthropogenic, or human-caused, causes (Leiserowitz et al, 2019). Many deeply embedded beliefs, attitudes, and values (the Dominant Social Paradigm) in societies, particularly societies in developed countries, are now understood to be "the source of the current ecological problems" (Atav, Altunoglu, \& Sonmez, 2014). Some of these attitudes, values, and beliefs endorse and encourage consumption, even over-consumption, of a variety of resources (Dunlap et al, 2000). Resources are being consumed at an unsustainable rate, causing damage on a global scale (Schultz, 2002). As these beliefs and behaviors are key to climate change, so is understanding how environmental beliefs and behaviors relate to other social attitudes. This paper contributes to the growing knowledge of the relationships between 
environmental beliefs and behaviors and social attitudes by exploring how right-wing authoritarianism is related to environmental beliefs and behaviors. 


\section{LITERATURE REVIEW}

\subsection{Environmental Beliefs}

Understanding people's attitudes concerning the environment is critical to understanding their overall belief system of the environment. Attitudes refer to evaluative judgements people make, in this case about the environment (Voas, 2013). Beliefs are the convictions that individual people maintain as true (Little, 84). The standard measure in social science literature of the pro-environmental beliefs people hold is the New Ecological Paradigm (NEP) scale, formerly known as the New Environmental Paradigm scale, which sums the scales of 15 attitudinal statements into a single score that is indicative of environmental beliefs (Dunlap et al., 2000). Specifically, it measures the following five beliefs: 1 . beliefs about the balance of nature- the belief concerning whether the balance of ecology is fragile to human disturbance; 2 . limits to growth- the belief that there are limits to society's economic growth fueled by environmental resources (the contrary is there are no limits to growth); 3 . antianthropocentrism/ecocentrism- the belief that nature has inherent value beyond what it provides for humans(the contrary is anthropocentrism); 4. exceptionalism- the belief that humans will be able to discern how nature operates and thus be able to control it (the contrary is anti-exceptionalism); and 5. Eco-crisis possibility- the belief that 
humankind will cause an eco-crisis through the over-use and abuse of nature (the contrary is eco-crisis impossibility) (Dunlap et al., 2000; Atav et al., 2015; Mcdermott, 2007). The 1978 New Environmental Paradigm scale included only 12 statements that measured the first three values.

The summation of these beliefs comprises a worldview, or paradigm. In opposition are two paradigms: the Dominant Social Paradigm, which is characterized by beliefs that nature is not fragile, there are no environmental resource limits to economic growth, anthropocentrism, exceptionalism, and there is no possibility of a humancaused eco-crisis; and the New Ecological Paradigm, which is characterized by beliefs that the balance of nature is fragile, there are limits to growth, ecocentrism, antiexceptionalism, that there is a possibly of an eco-crisis. The summed score of the 15 attitudinal statements place people on a bipolar scale, with one end indicating environmental beliefs consistent with the Dominant Social Paradigm and the other indicating beliefs consistent with the New Ecological Paradigm. These social paradigms are not static. Dunlap et al. (2000) notes that this outlook is "responsive" to personal experiences and information (from the government, scientists, and/or media) concerning climate problems (439). As people internalize new information and experiences, their attitudes about the environment should change, which can lead to changes in their beliefs about the environment.

Researchers have identified some methodological issues with the original 12item 1978 NEP scale, causing Dunlap et al. to revise the original scale in 2000, creating 15-item scale measuring respondents' endorsements of ecological worldviews (Dunlap 
et al., 2000). The biggest methodological issue concerned the debate about its dimensionality (Anderson, 2012). Dunlap et al. attributed this issue in the original scale to an imbalance in the number of pro- and anti-NEP statements; the scale worded 8 statements as pro-NEP while only 4 statements were worded as anti-NEP. Further, all four of the anti-NEP statements focused on anthropocentrism, which they report was found to comprise a distinct dimension of its own in other studies (Dunlap et al., 2000). However, their factor analysis of the new scale creation shows conflicting evidence for a one-factor and a four-factor solution. Atav et al. argues that, conceptually, it should be considered a 5-dimensional scale as the scale was revised to address the five hypothesized facets that create an ecological worldview: balance of nature, limits to growth, anti-anthropocentrism, exemptionalism, and ecocrisis, although their analysis shows evidence for a 2-factor solution (2015). In addition to balancing the scale and more thoroughly addressing all five facets, Dunlap et. al. revised statements to remove outdated and sexist terminology (Dunlap et al., 2000).

Understanding pro-environmental beliefs and attitudes, as well as predictors, can be confusing given that the literature frequently contradicts itself. The following demographic factors have emerged as a trend in the literature, but it is important to note that many, if not all, have been shown to be nonsignificant in at least one study. For example, one such controversial trend is that younger, better educated people are more likely to hold pro-environmental beliefs and attitudes (Arcury \& Christianson, 1990; Dunlap et al., 2000; Gifford \& Nilsson, 2014; Lee and Zhang, 2008; Xiao et al., 2019). Gender has also been shown to influence pro-environmental attitudes and 
beliefs; women are more likely to hold pro-environmental beliefs and attitudes (Ziegler, 2017). People who identify as liberal are also more likely to agree with the new ecological paradigm (Dunlap et al., 2000; Gifford \& Nilsson, 2014; Johnson et al., 2004; Xiao et al., 2019). Status as a university student may also play a role; a 2015 study showed that university students generally held views that conformed with the New Ecological Paradigm rather than the Dominant Social Paradigm (Atav et al., 2015).

The NEP scale has been widely used to predict specific pro-environmental beliefs and attitudes. For instance, Ziegler found that a higher NEP score is associated with beliefs that climate change exists (2017). Lee and Zhang found that those with higher NEP scores identified more causes of climate change and tended to identify humans more often as the cause of climate change as opposed to climate change being the result of a natural process (2008). The NEP scale has been shown to powerfully predict ecological concern (Xiao et al., 2019).

Another finding of interest comes from a longitudinal study of Kentucky residents. The study found that people located in counties who had experienced an environmental crisis (specifically, a drought that led to water usage restrictions) significantly increased their agreement with the new ecological paradigm compared to their agreement before the crisis (Arcury \& Christianson, 1990). This suggests that the experience of environmental abnormalities can cause individuals to alter their attitudes and beliefs pro-environmentally. 


\subsection{Environmental Behaviors}

Just as beliefs about the environment are important to understand, so are the behaviors of individuals that impact the environment, specifically Pro-Environmental Behaviors (PEB). PEB includes both committing actions that are beneficial to the environment and refraining from actions that harm it (Lange \& Dewitte, 2019). Kaiser and Kibbe (2017) note that "all behaviors have ecological consequences" because all behavior is consumptive, to a degree, of the surrounding environment (pg 1). This could be as simple as breathing to the more impactful level of the $\mathrm{CO} 2$ released by consuming gas to drive a car. Typically, people do not intend to harm the environment with their behaviors, but nor do they always intend to help the environment (Kaiser and Kibbe, 2017).

It is important that PEB be measured in a way that considers whether the behaviors are being carried out, as well as the environmental impact those behaviors have. Some behaviors have more of a positive impact on the environment than other pro-environmental behaviors. It is also important that the measurement accounts for the context in which those behaviors take place. Some pro-environmental behaviors are easier or harder to carry out based on the setting the actor is located in. For example, Walton and Austin (2011) found that those who had access to curbside recycling were significantly more likely to recycle than those who do not have access. It is likely that making recycling available to residents makes it easier to recycle, whereas those who do not have curbside recycling likely find it more difficult to recycle 
In previous research, PEB has been measured in a multitude of ways. Markle identified no less than 42 unique PEB measures (2013). Lange and Dewitte found 33 measures in 2019, several of which were created after Markle's 2013 review. The most established measure is the General Ecological Behavior (GEB) scale. It originally consisted of 38 items but was updated in 2000 and now contains 51 items; 43 represent a variety of ecological behaviors and 8 non-environmental prosocial behaviors (Kaiser \& Wilson, 2000). According to Lange and Dewitte's review of PEB scales and research, the GEB scale is the most frequently cited (2019). However, many who utilize this scale to measure PEB choose item subsets (Davis, Green \& Reed, 2009, 28 items; Hill, Figueredo \& Jacobs, 2013, unspecified number of items), which may then be mixed with items from other scales or independent items (Eom et al., 2018, 3 scales; Vesely, Brick \& Klöckner, 2019, unspecified number of items).

The variety in methods used to measure PEBs, even when drawing from the same scale, has created a measurement inconsistency. This measurement inconsistency has led to a plethora of research on PEBs that is difficult to interpret. Looking at demographic outcomes, we see that age seems to have a positive association with PEB, which is a contrast to the relationship between age and pro-environmental beliefs (Enzler \& Diekmann, 2015; Gifford \& Nilsson, 2014; Olli et al., 2001; Johnson et al., 2004; Pinto, Nique, Anana, \& Herter, 2011; Swami, Chamorro-Premuzic, Snelgar, \& Furnham, 2011; Walton and Austin, 2011). Markle found age did not impact PEB (2019).

Research on gender and PEB is inconclusive; some studies have found that women are more likely than men to exhibit one or more PEBs (Enzler \& Diekmann, 
2015; Gifford \& Nilsson, 2014; Johnson et al., 2004; Prati, Albanesi \& Pietrantoni, 2017;

Zelezny, Chua, \& Aldrich, 2000) while others have found that there is no relationship (Markle, 2019; Walton and Austin, 2011). Social economic status (SES) has also been shown not to have a statistically significant relationship with PEBs (Eom, Kim, Sherman, 2018; Grob, 1995). Income, a facet of SES, has been shown to positively predict PEBS (Walton and Austin, 2011), to negatively predict PEBs (Enzler \& Diekmann, 2015), and to have no statistically significant effect on PEBs (Markle, 2019). Education, another of many facets comprising SES, has also been shown by some research to have a positive impact on PEB (Gifford \& Nilsson, 2014; Ollie et al., 2001). Political ideology has been found to impact PEB; those who hold a liberal political ideology are more likely to display PEBs (Johnson et al., 2004).

How, then, do pro-environmental beliefs and pro-environmental behaviors relate to one another? Many researchers have found positive correlations between proenvironmental beliefs and pro-environmental behaviors. Most have found weak relationships (Poortinga et al., 2016; Van Riper et al., 2018). Eckes and Six (1994) found an average correlation of 0.26 in their meta-analysis of 17 studies. Some studies have found moderate or strong relationships (Chen et al., 2018; Grob, 1995; Lee et al., 2014; Schahn \& Holzer, 2016), while many have found no relationships (Maloney, Ward \& Braucht, 1975). Gifford (2011) explains this tenuous relationship with seven psychological barriers that together hold 29 specific manifestations. These manifestations include optimism bias (individuals downplay that the severity of climate change predictions will manifest) and perceived inequity (individuals reason that they 
should not bother changing because they think others around them will not). Pagiaslis and Krontalis (2014) argue that beliefs do play a part in behavioral intentions, but only if those beliefs are first informed with environmental knowledge and concern.

\subsection{Authoritarianism}

Following WWII, there was an increase in academic interest that sought to understand how the Holocaust could have happened. Authoritarianism, first articulated by Adorno, Frenkel-Brunswick, Levinson, and Sanford in 1950, was conceptualized to explain the rise of Nazis and the passivity of many of the 'ordinary' German citizens. They (1950) operationalized authoritarianism as a personality dimension comprised of nine covarying traits measured with their famous California Fascism Scale (F Scale) which consisted of (in its final form) 29 Likert scaled items that attempted to operationalize what they theorized were the major nine personality traits that created fascistly-oriented people (Camilleri, 1959). These traits are Conventionalism, Authoritarian Submission, Authoritarian Aggression, Anti-Intraception, Superstition and Stereotypy, Power and Toughness, Destructiveness and Cynicism, Projectivity, and Concern about Sex (Adorno et al., 1950). However, this scale was subsequently shown to be flawed; the items were not balanced, introducing acquiescence bias (a bias describing the tendency of survey respondents to positively respond to positively worded questions) (Altemeyer, 1981). Due to major theoretical and psychometric problems, unidimensionality could not be established (Altemeyer, 1981).

To address these problems, Altemeyer devised his Right-Wing Authoritarianism (RWA) scale in 1981 as an alternative to the F Scale, which has been 
the standard authoritarianism scale in sociological literature for nearly four decades. His theory of right-wing authoritarianism ('right-wing' referring to those who support whomever they perceive to be the authorities) posits authoritarianism as a unidimensional personality trait made up of three covarying orientations: authoritarian submission, authoritarian aggression, and conventionalism.

Authoritarian submission refers to the high degree to which individuals quickly adhere to the instructions from those considered to have some sort of authority over others (Altemeyer, 1996, pg. 9). Conventionalism characterizes the strong adherence to, and expectation for others to adhere to, the social norms of a society as dictated and/or exemplified by authorities (Altemeyer, 1996, pg. 11). Authoritarian aggression describes the characteristic of desiring and inflicting intentional and harsh harm, psychological or physical harm, on individuals or groups who are perceived to transgress the directions of authorities as a punishment when the aggressors believe it is helpful to or approved by authorities (Altemeyer, 1996, pg. 10). A right-wing authoritarian can present one or more of these orientations.

A great portion of the right-wing authoritarianism research utilizes the RWA scale. Demographically, research has found positive correlations between age and authoritarianism (Duriez \& Van Hiel, 2002; Rubenstein, 1996) and negative correlations between education and authoritarianism (Duriez \& Van Hiel, 2002; McDermont, 2007; Rattazzi, Bobbio, Canova, 2007). Several studies have found no relationship between gender and authoritarianism (Altemeyer, 1998; Cribbs \& Austin, 2011; Heaven \& St. Quintin, 2003; Peterson, Doty, \& Winter, 1993; Rubenstein, 2002; Zakrisson, 2005). 
Broadly, the research utilizing the RWA scale concludes that right-wing authoritarians tend to identify as politically conservative and orthodoxly religious and tend to be highly nationalistic, ethnocentric, and prejudiced against socially deviant individuals or groups (Altemeyer, 1981, 1996; Duckitt, 2009; Duckitt, et. al., 2010, Pratto et. al., 1994, Heaven \& St. Quintin, 2003; Rubenstein, 1996). Other notable findings include a positive correlation between authoritarianism and traditional gender attitudes (McDermont, 2007) and lower authoritarian levels for social science students and humanities students (Rubenstein, 1996).

The scale has been used globally in authoritarian research. Altemeyer tested it in Canada (1996), Zakrisson (2005) tested it with Swedish high school and college students, Duckitt (1993) tested it with white South Africans, McDermont (2007) tested it with Argentinian adults, and Mavor, Louis, and Sibley tested it in New Zealand with undergraduate students (2010). Many researchers have tested it in Australia (Heaven, 1984; Heaven and Quintin, 2002; Ray, 1985) and Italy (Aiello, Chirumbolo, \&Leone, 2004; Giampaglia \&Roccato, 2002; Rattazzi, Bobbio, \& Canova, 2007), and Rubenstein tested it in Israel with Jewish students $(1995,1996)$ and Palestinian students (1996) while Duckitt et al. tested it with adults in Israel (Duckitt et al., 2010).

The RWA scale's validity and reliability are highly controversial. Altemeyer's conceptualization of authoritarianism as unidimensional with three constructs (authoritarian submission, authoritarian aggression, and conventionalism) is supported by some researchers (Altemeyer, 1981, 1996; Duckitt, 1991, 1993). Indeed, their studies shows that the RWA scale has high reliability and validity. Many studies have found a 
Cronbach's alpha of at least .80 or above, demonstrating the reliability the scale (Bizumic \& Duckitt, 2018; Duckitt, 1993; Duckitt, et al., 2010; Duckitt \& Fisher, 2003; Rattazzi, et. al., 2007; Zakrisson, 2005). Findings such as strong correlations between authoritarianism and political orientation or prejudice demonstrate its ability in meeting validity criterion.

However, other researchers have found substantial problems in the RWA scale's ability to meet validity criterion (e.g. Funke, 2005; Duckitt et al, 2010; Gray and Durrheim, 2006; Rattazzi, et al., 2007). The research, largely the more recent research, is conflicted on whether right-wing authoritarianism is, as theorized by Altemeyer, unidimensional or, as is becoming increasingly supported, multidimensional. Altemeyer viewed the covariance between the three components he identified as what creates the singular dimension of right-wing authoritarianism. Yet, many researchers see a disconnect between his theoretical three factors and operationalized RWA scale's unidimensionality (Funke, 2005). Because Altemeyer viewed this overlap as the crux of authoritarianism, many statements measured two or even all three of the components at once, resulting in many double- or triple-barreled statements. For example, Funke (2005) found 11 double-barreled items and 3 triple-barreled items. This makes it impossible to use the scale to analyze just one of the three components, and researchers can never be sure which component is really driving the responses to those double- and triple-barreled statements (Duckitt et al, 2010). Further, Altemeyer confounds the item content and wording direction of his scale; there is no scale balance of statements based on component content or direction of wording. Those statements 
can then create a false appearance of unidimensionality, which can be difficult to refute given that the components cannot be tested separately to ascertain whether they are indeed dimensions of their own right or some other possible set of dimensions (Litwak, 1956).

For example, Gray and Durrheim (2006) examined the results of three South African studies utilizing the RWA scale. The samples differed in each study; one studied 63 police officers, one studied 107 English-speaking university students, and the last studied 104 white residential students. The first two studies were inconclusive on the dimensional structure of authoritarianism. The last study showed via a principal components factor analysis that three factors explained $20 \%, 15 \%$ and $10 \%$ of the total variance. Factor 1 had an acceptable internal consistency of $\alpha=0.70$, but Factor 2 ( $\alpha=$ $0.52)$ and Factor $3(\alpha=0.40)$ were not internally consistent. Further, RWA did not correlate with questions concerning racism and conservatism. This raises questions concerning the dimensionality; the researchers could not confirm that authoritarianism is unidimensional as theorized by Altemeyer, but they concede that possible cultural differences and non-representative samples could impact their findings.

Rattazzi et al. (2007) sought to create a short authoritarianism scale in Italy as an alternative to the translated version of Altemeyer's RWA scale (Aiello, Chirumbolo, \& Leone, 2004; Giampaglia \& Roccato, 2002). They conducted two studies; one with university students to create their short scale and one with a convenience sample of adults to validate their short scale. They investigated the link between authoritarianism and prejudice, both subtle and blatant, against Islamic immigrants. Their first study 
included the Italian version of the RWA scale from which they created their short scale. They determined, after running a principal component analysis with an oblique rotation, that a two-dimensional ("authoritarian submission and aggression" and "conservatism") 14-item scale was optimal. It was found to be reliable, correlating highly $(0.97)$ with the full RWA scale and both subtle and blatant anti-Islamic prejudice, while correlating negatively with positive attitudes towards Islamic immigrants. Their second study, in which they tested the short scale with a convenience sample of adults, supports these findings, although the two-factor model was not quite as strong as found in the first study. They conclude their discussion of authoritarian dimensions by highlighting that their results "permit consideration of two dimensions of authoritarianism" (Rattazzi, et al., 2007).

Duckitt and Fisher (2003) studied 280 psychology university students in New Zealand who were randomly assigned to either the threat group, the secure group, or the control group and given a scenario corresponding to their group that depicted the future in a decade. The threat group imagined New Zealand was in economically and socially disintegrating, characterized by "high rates of crime, violence, and social conflict" (page 206). The secure group imagined that New Zealand's economy was booming, and crime, unemployment, and poverty rates were near zero. The control group imagined that New Zealand remained basically the same as it was in 2003- the economy was moderately good, and that society was fairly cohesive. They were then asked to complete a survey that included Altemeyer's RWA scale as if they were living in that future scenario. The researchers then conducted an exploratory principal 
components analysis of the RWA scale, finding two factors: authoritarian attitudes (Altemeyer's authoritarian aggression items) and conservative attitudes (Altemeyer's authoritarian submission and conventionalism items).

This directly contrasts Rattazzi et al.'s (2007) findings; while Duckitt and Fisher (2003) establish authoritarian aggression as its own dimension, Rattazzi et al. combine authoritarian submission and aggression. Their conservatism dimension consists of conventionalism items, yet Duckitt and Fisher's conservative dimension consists of both authoritarian submission and conventionalism items. These findings point out the difficulties that arise in determining what components are driving the responses to double- or triple-barreled questions. They also mask understanding potential cultural differences in response to these dimensions.

To further test dimensionality, Duckitt and Fisher then ran a confirmatory factor analysis to compare a single-factor solution to a two-factor solution, both with and without method factors, because of the correlation between content and wording direction. Without method factors, the two-factor solution modeled the data much better than the single-factor model. With method factors, the two-factor model "provided a better empirical fit for these items than did a single content factor".

Mavor, Louis, and Sibley (2010) explored the possibilities of one, two, and three dimensions in Altemeyer's RWA scale, surveying 545 undergraduate students in New Zealand. The researchers conducted a factor extraction using a promax rotation method, finding that the RWA scale, when compared to one dimension, fits better to 
both two dimensions ("aggression" and "conventionalism") and three dimensions (additionally, "submission"), both before and after correcting for acquiescence bias. Submission loads onto far fewer items than the other factors, but many of Altemeyer's statements in the scale concerning submission are also confounded with another component causing those items to load more heavily with the other two factors. They then created ten item parcels in order to concentrate on the higher order structure and found that right-wing authoritarianism to be "a higher-order construct representing three conceptually and empirically distinct dimensions" (Mavor, Louis, and Sibley, 2010).

Similarly, Funke (2005) used structural equation modelling to demonstrate the validity of a three-dimensional authoritarianism construct. They started by deconstructing the double- and triple-barreled items to create 'pure' items, resulting in a shorter, balanced 12 -item scale. Then, combining samples from nine different studies to create a sample of 3,095 adult internet users, they ran a confirmatory factor analysis, creating three different models: a single-factor model, a simple three-dimensional model, and a three-dimensional model with method factor. The single-factor model was a significantly worse fit than the other two three-dimensional models. A second study using a sample of 416 internet users analyzed the differences in interpreting authoritarianism's impact regarding the respondents' determination to a question asking how many years of imprisonment they would impose on someone convicted of sexual abuse (standardized with a uniform fictitious newspaper article) when authoritarianism is measured as a singular global score versus a score for each of the three dimensions. Running a simple regression with the global score, they found no 
significant relationship between authoritarianism and the length of time respondents would imprison a sexual abuser. However, when they ran a multiple regression using a score for each component, they found significant relationships for all three dimensions, providing evidence of interdimensional discrepancy and displaying how significant correlations "can be completely masked by the traditionally applied global RWA score".

Funke's final study investigated the intradimensional discrepancy. The sample consisted of 368 German internet users responding to a poll on contemporary political issues. Questions on segregation, integration, and assimilation and the Capitalist Value Scale were regressed on authoritarianism, as both a global score and scored threedimensionally. RWA globally predicted the support of capitalist values, segregation, and assimilation and the opposition of integration. The three-dimensional model showed aggression and conventionalism predicted capitalist values, aggression and submission predicted segregation, aggression, submission, and conventionalism predicted assimilation, and aggression and submission predicted integration. These results demonstrate how the use of a single score for authoritarianism hides the differences between the three dimensions. Further, it calls standard validation criterion into question; how many relationships have been misattributed as either significant or insignificant due to the improper operationalization of authoritarianism?

Not only does the RWA scale improperly identify the number of dimensions that constitutes Right-Wing Authoritarianism, it very likely that Altemeyer's original conceptualization of authoritarianism as a personality trait was theorized incorrectly, as was hinted in the earlier summations of authoritarian research. Many researchers 
believe authoritarianism is better understood as a social attitude (Duckitt \& Fisher, 2003; Gray \& Durrheim, 2006). Personality traits are dispositional, or, in other words, relatively stable and consistent behaviors in an individual across a variety of circumstances, whereas social attitudes are evaluative judgments about various facets of society (Voas, 2013). The RWA scale is composed entirely of statements pertaining to social attitudes rather than dispositional tendencies.

Duckitt and Fisher's (2003) study provides convincing evidence for this reconceptualization. When contrasted to the control scenario, the threat scenario increased authoritarianism levels, while the security scenario had no impact. This increase implies then that authoritarianism is not necessarily a consistent behavior across time, but a social attitude that is malleable and adaptable to societal influences, particularly threatening influences. The researchers point out that historically there are multiple examples of socially threatening situations that lead to "rapid and dramatic shifts toward more authoritarian social attitudes". One such example is the social crisis in Germany after WWI that resulted in Germans facilitating Hitler's ascent to political power and Nazi rule, likely due (at least in part) to a precipitous shift towards more authoritarian attitudes. However, it appears that authoritarian levels are slow to decrease. Duckitt and Fisher explain this by pointing out that research on social values correlated to authoritarianism are slow to shift, perhaps shifting over generations. It may be thus that experiences of social threats require long periods in which authoritarians can establish a "deeply rooted sense of interpersonal trust and satisfaction" before their attitudes show a marked shift. 
Additional problems with Altemeyer's RWA scale include the length; it held 30 items, for which Altemeyer did not publish an empirically verified short-form scale at that time (Altemeyer, 1996). The research is inconclusive on whether lengthy scales are bad for either or both item response and overall non-response (Bizumic \& Duckitt, 2018; Edwards, Roberts, Sandercock \& Frost, 2004; Marek, Peterson, Henning, 2017) or not (Cleopas, Kolly \& Perneger, 2006; Robb, Gatting \& Wardle, 2017; Stolzmann et al., 2018). Although the impact of survey length on response rates is called into question, it is undeniable that, for one reason or another, most research that has been done with the RWA scale has used some version of a shorter scale. Altemeyer eventually created a short-form RWA scale that held 20 items (Altemeyer, 2007), but this revision does not seem to be widely utilized in authoritarian research, likely because short-form scales had already been established by other researchers.

These issues with the RWA scale have resulted in unstandardized right-wing authoritarianism research, making the results difficult to interpret. Researchers' desire to shorten the length of the RWA scale has resulted in a large portion of the right-wing authoritarian research being evaluated with different combinations of his 30 items. Some researchers have selected at random fewer items (Duckitt \& Fisher, 2003). Others have established their own short-form RWA scale to address dimensionality and length issues, which is then sometimes used by others. Duckitt (1991) established the 14-item RWA scale, which was originally shown to be unidimensional (Gray \& Durrheim, 2006). Rattazzi et al. (2007) also developed their own 14-item short-form RWA scale with two dimensions: a dimension combining submission and authoritarian aggression and 
conservatism dimension. Dunwoody and Funke (2016) developed the 18-item ASC, Funke (2005) developed the 12-item German RWA3D, Schultz and Stone (1994) developed a shortened RWA scale of 8 items, Aichholzer and Zeglovits (2015) developed the 6-item Balanced Short Scale of Authoritarian Attitudes (B-RWA-6), the 2016 American National Election Study (ANES) included three items from the RWA scale (ANES, 2017), and Dunwoody and Funke (2016) recently developed the AggressionSubmission-Conventionalism (ASC) scale.

Of the all the scales developed, the Authoritarianism-ConservatismTraditionalism (ACT) scale (Duckitt et al., 2010) is the most theoretically and statistically sound measure (Bizumic \& Duckitt, 2018). Duckitt et al. reconceptualized right-wing authoritarianism not as a personality construct but as a multi-dimensional social attitude that articulates the overall degree of an individual's support or endorsement of authorities subordinating individual's autonomy to the collective in order to ensure the security of the collective. Three methods for achieving subordination have been identified: authoritarianism is analogous to Altemeyer's concept of authoritarian aggression, conservatism refers to Altemeyer's authoritarian submission concept, and conventionalism became traditionalism. These comprise the three dimensions of rightwing authoritarianism. Authoritarians believe that when individuals obey the commands, rules, and laws from authorities, security within the collective is achieved; ignoring or disobeying these directives introduces insecurity. In order to achieve and maintain security, individuals must obey the commands of the authorities. When individuals transgress directives, they become deviants. Deviants have the potential to 
destroy the security of the collective. In the name of ensuring collective security, authoritarians support or endorse subordinating deviants to the social authorities of the collective through harsh punishment and "coercive social control" (Duckitt et al., 2010, pg. 690).

Conservatives believe the unity of society ensures the security of the collective. The social status quo, determined by the authorities, of the collective is viewed as important to maintain for the sake of unity. Their attitudes, therefore, tend to support and endorse obedience and respect to the dominant social institutions and authorities in the collective (Duckitt et al., 2010). Individuals that do not conform with or threaten the status quo are seen as deviants. Deviants might be critical or questioning of authorities or possess a rebellious attitude. This represents a threat to the unity of the society, which threatens the security of society. Thus, conservatives value passive submission to society's authorities in maintaining the status quo as a method of ensuring collective security.

Traditionalists believe that the traditional lifestyle of the collective imparts important social values from one generation to the next. When individuals in the collective across characteristics like (but not limited to) race, ethnicity, age, and particularly generation all share the same prescriptive traditional lifestyle, they share the same social values, solidifying the security of the collective. Traditionalists support authorities in maintaining these traditional lifestyles by "resisting 'modern' liberal, secular, open, lifestyles, norms, and morality" (Duckitt et al., 2010, pg. 691). They view those who deviate from the traditional lifestyle- in other words, those who accept 
'modern' social changes- as individuals rejecting not just the lifestyle but the values set by the previous collective authorities and endorsed by the present collective authorities. Traditionalists fear this rejection will spread uncertainty about the social values. A lack of shared social values can lead to insecurity in the collective.

The researchers developed and refined this scale over the course of five studies conducted in New Zealand sampling university students, the United States sampling adults, Israel sampling a mixture of university students and adults, and Romania sampling university students. Four confirmatory factor analyses were run for each study, testing a 1- and 3-factor model and all three 2-factor combination models. The results consistently indicated that a 3-factor model, as hypothesized, was the best fit. These three factors are the subscales Authoritarianism (designated as A), Conservatism (designated as C), and Traditionalism (designated as T). In their five studies, the ACT scale associated significantly with every validity criterion as hypothesized by the researchers. The scale significantly predicted higher levels of religiosity and religious fundamentalism, but only the T subscale significantly predicted these relationships. ACT globally positively predicted support of greater military force (A), nuclear weapons (A), banning protests ( $A$ and $C$ ), drug raids without warrants ( $A$ and $T$ ), ethno-cultural identification ( $T$ ), more severe prison sentencing $(A)$, and negatively predicted support for the decriminalization of marijuana (T) and support for gay rights (T).

The full ACT scale includes 36 items; the short form scale is comprised of a subset of 18 items. Both the long- and short-form ACT scale have been successfully used in other studies, supporting its validity and reliability as a 3-dimensional scale (Duckitt \& 
Bizumic, 2013; Devine-Wright, Price, \& Leviston, 2015; Dunwoody \& Funke, 2016; Sinn \& Hayes, 2018; Bizumic \& Duckitt, 2018; Ludeke, Klitgaard, Vitriol, 2018; Crowson \& Brandes, 2017). The ACT scale globally predicted a negative association between rightwing authoritarianism and taking part in demonstrations (C) (Duckitt \& Bizumic, 2013). Bizumic and Duckitt (2018) found that the ACT scale as a whole also significantly correlated as expected with validity criterion such as nationalism, blind patriotism, prowar attitudes, anti-immigrant attitudes, and ethnocentrism. Another 2018 study further demonstrates short-form ACT's validity and reliability when using it to predict candidate support in the U.S.'s 2016 Presidential election. The ACT scale as a whole positively predicted support for candidate Cruz ( $A$ and $T$ ) and Kasich $(C)$ and negatively predicted support for Sanders (A and T) and Clinton (C), while only subscale A predicted support for Trump (Ludeke, Klitgaard, Vitriol, 2018). In 2017, Crowson and Brandes found that authoritarianism and traditionalism are both associated significantly with a person's likelihood of voting for Trump over Clinton.

\subsection{Right-Wing Authoritarianism, Environmental Beliefs, and Environmental Behaviors} Schultz and Stone's 1994 study was one of the earliest studies examining the relationship between right-wing authoritarianism and pro-environmental attitudes and beliefs. In their first study, they used 8 items from the RWA scale and 7 items from a River Environmental scale. They used a convenience sample of 80 people who attended two controversial and polarizing city planning board meetings that met to discuss a proposal to build a large energy plant locally. They hypothesized that authoritarians would support the construction while environmentalists would oppose it. The results 
confirmed their hypothesis, and they found that $62 \%$ of the variation in support/opposition for the plant could be explained by the combination of authoritarianism and environmentalism. Their second study utilized the original 12-item NEP scale and the full 30-item RWA scale which was administered to 87 undergraduate students. They found a significant correlation of -0.54 between the NEP and RWA scores.

Devine-Wright et al.'s 2015 study, utilizing the short-form ACT scale and 2 statements indicating belief in anthropogenic climate change, showed that authoritarianism negatively associates with belief in human-caused climate change and a sense of belonging to the Earth globally. Further, authoritarianism partially mediated a significant positive relationship between global place attachment and belief in anthropogenic climate change.

Stanley and Wilson (2019) conducted a meta-analysis of 40 studies, moderating for scale type and sample type measured as students or general population. They found that authoritarianism is significantly negatively associated with environmentalism. Contrary to their hypothesis, controlling for social dominance orientation and political orientation did not diminish the strength of the relationship. Further, they found the strength of this relationship does not significantly differ between students and the general population, nor does it differ by scale type. Finally, authoritarianism negatively correlated to all four categorizations of their environmental measure (climate change belief, support for action, green politics, pro-environmental attitudes). 
Finally, a 2012 study conducted in Germany found interesting results

(Reese \& Schiller). In Germany, there is a social and legal context which promotes and enforces pro-environmental behaviors. Their sample consisted of 56 Germans obtained through in-person convenience sampling. They found, using Funke's 2005 RWA-3d scale and the 15-item NEP scale, that authoritarian submission was positively associated with pro-environmental beliefs, meaning the more submissive one was to authorities, the higher their NEP scale score. Authoritarian aggression, however, was found to have a negative relationship with environmental beliefs and there was no significant relationship between conventionalism and environmental attitudes and beliefs. This finding highlights the importance of the societal context in which one is from when hypothesizing and interpreting results, as well as support the concept of submission as accurate.

There appear to be only two studies that looks at the specific environmental behaviors of authoritarians: Altemeyer's 1994 Global Change Game (1996, 130-136) and Altemeyer's 1998 reprisal. The Global Change Game is a "sophisticated three-hour simulation of the earth's future, usually involving 50-70 players who are assigned to various regions on a large map of the world" and are given a series of situations (for example, an ozone crisis) that they have to solve (somewhat similar to Model UN) (Altemeyer, 2003). In the first study, low-level authoritarians played the Global Change Game, and, through cooperation, fixed the ozone layer, amongst other actions that led a generally "peaceful" period (Altemeyer, 2003). When high-level authoritarians played, they ended the world in a nuclear holocaust. When given a second chance (reverting to 
before the nuclear holocaust), "conventional wars still broke out, and global problems of overpopulation, hunger, and disease went unaddressed" (Altemeyer, 2003).

In the 1998 reprisal, Altemeyer recruited just high-level RWAs who varied on their levels of social dominance. Both nights resulted in a dismal future; although the second night did result in a global conference to address the ozone layer, neither night saw a united effort to address the ozone and the worlds ended in high rates of death, disease, and environmental decay (Altemeyer, 2003). Altemeyer noted that high-level RWAs tended to be ethnocentric and fearful, used much of their resources to fund their militaries, and applied an individualistic regional approach to responding to situations (2003). This suggests that authoritarianism is possibly negatively related with proenvironmental behaviors.

\subsection{Research Aims of the Current Study}

Overall, the literature shows that authoritarianism seems to be related negatively to pro-environmental beliefs and attitudes. This, however, has not been determined with the ACT scale, which is better operationalized than its predecessors. There is also a gap in the literature surrounding the relationship between authoritarians and pro-environmental behaviors.

Furthermore, this data was gathered in a unique situation: the onset of COVID19 related restrictions and regulations in America. Research has shown that situations which increase social threat can stimulate authoritarians to become more authoritarian (Duckitt \& Fisher, 2003). However, that research studied a social threat scenario in 
which lawlessness, government spending, unemployment, violent and petty crime, and violent riots have all increased and social welfare, economic security, and confidence in the police's ability to keep peace have all decreased in the years leading up to the scenario. This presumably constitutes the researchers' perceptions of social threat.

In the current state, it is unknown if lawlessness and crime has increased. Perceptions of this may differ because unprecedented rules and regulations are being put forth by the government to mitigate the impact of COVID-19. Some may view these as lawful and, thus, perceive anyone who does not abide by them (such as refusing to wear a mask in public spaces) as being unlawful or committing a crime. However, many do not view these regulations and rules as lawful, and, thus, disregard these and consider themselves or others to be lawful when refusing to comply. Additionally, the increase in the government implementing restrictive rules and regulations has never been studied, and it is unknown how this impacts authoritarians. Government spending and unemployment have increased, but social welfare has been expanded, although there is much debate about whether welfare has been expanded enough to offset the economic instability many people are facing. Violent riots do not have appeared to increase as of writing, but it remains unknown, as is the level of general public confidence in the police. Overall, it is difficult to assess whether and how the COVID-19 situation has impacted people's authoritarian views.

Additionally, environmental beliefs may be impacted. Prior to COVID-19, the state of the environment was in the worst shape it has been in in living memory. The U.S. has experienced severe wildfires, flooding, and hurricanes, amongst other harsh 
weather within the last two years. The literature suggests that experiencing a climate crisis can stimulate people to become have stronger pro-environmental beliefs and attitudes (Arcury \& Christianson, 1990).

The literature seemingly does not address the opposite; how does a healing environment impact pro-environmental attitudes and beliefs? While the environment is, overall, in terrible shape during the COVID-19 crisis, the restrictive rules implemented by the government have significantly decreased air and auto travel, as well as manufacturing production, leading to a major decrease in greenhouse gas emissions, so much so that the environment is visibly improving (although it is not improving enough to reverse climate change). For example, Los Angeles, a major international hub, has had a few weeks in which the skyline was visible due to the lack of smog emissions from travel. People have also increased their presence in nature; encouraged by the government, people have taken to walking outside to mitigate the psychological impact of quarantining. It is unknown how this could impact one's organizing social paradigm, although a reasonable hypothesis suggests it might encourage more pro-environmental attitudes and beliefs due to the environment visibly healing as a direct result of people, yet it might result in anthropocentric views as the increased appreciation for a cleaner environment still might rest on the basis of the benefit being for humanity.

A study, given this context, may yield interesting results. The goal of this thesis is to investigate the relationship between right-wing authoritarianism and proenvironmental beliefs and the relationship between right-wing authoritarianism and 
pro-environmental behaviors, as well as to clarify the gaps previously identified in the literature. 


\section{METHODS}

\subsection{Participants and Data Collection Procedures}

A survey was best suited for this research as opposed to qualitative methods because it allowed the investigators to tap into pro-environmental beliefs, proenvironmental behaviors, and right-wing authoritarianism, and quantify these in ways that enable the investigators to research correlations. An online survey suited this research project best because the survey was accessible when the University closed inperson courses in March in response to COVID-19, the survey was functional on both computers and mobile devices, it was cost-effective, it allowed the researchers to contact students enrolled in the fall of 2019 , and it minimized the risk of transcription errors.

The convenience sample is comprised of 343 students attending a midwestern R1 University who were enrolled in intro-level sociology courses (both online and inperson) in the spring semester of 2020 or were enrolled in intro-level sociology courses conducted online during the fall semester of 2019. Students in these courses were given the option by their course instructors to opt-out of sharing their email addresses with the researchers. 343 invited participants did not opt out and their emails were given to 
the researchers. They were emailed a survey invitation (see appendix A for communications) through Qualtrics survey software explaining the purpose of the survey, requesting their participation, and explaining that their participation is voluntary, and their data is held confidential. The survey invitation was addressed to each student by name, which has been shown to increase response rates (Muñoz-Leiva et. al, 2010). The invitation also included a unique online survey link, which ensured that participants were not able to take the survey more than once and has been shown to increase response rates (Joinson, Woodley \& Reips, 2007). Invited participants were emailed up to two reminders to complete the survey; of studies that specify how many reminders are sent, this is the most common number of reminders used in online student web surveys (Van Mol, 2017). The first reminder was sent 7 days after the initial invitation (Archer, 2007). The second and final reminder was sent 12 days after the initial invitation (Saleh, Bista, 2017). Respondents only received reminders if they had not yet taken the survey as of when the reminder was sent (Schirmer, 2009). The survey remained open for two weeks. 61 students responded. Using casewise deletion, analytic samples sizes ranged from 53 to 60 respondents. The response rate, calculated using AAPOR's RR2 formula (2016), is $17.78 \%$. A variety of unexpected circumstances beyond the researcher's control occurred during data collection.

Briefly, data was collected during the on-set of COVID-19 university-wide and state-wide shutdown; the chaotic period likely reduced the present study's response rate. Additionally, the university implemented an email flagging system that flagged all emails not sent from a university email address as potential spam. Thus, survey 
invitations and reminders sent through Qualtrics were flagged as potential spam or phishing emails, likely reducing the response rate.

Within the survey, respondents were not able to alter their choices once moving to the next survey page. Respondents were prompted to by Qualtrics to answer any questions they left unanswered if they attempted to move to the next page, but they were not required to provide an answer. Respondents were shown a progress bar that displayed the text "Current Progress $x \%$ ", with $\mathrm{x}$ being the percentage number. For information on page breaks, refer to appendix A. The survey was conducted online using Qualtrics survey software, and data was collected in March and April 2020. Of the 57 respondents who completed the survey (albeit with missing values), the median time spent taking the survey was 10 minutes and 20 seconds. Respondents received no incentives or compensation. Those under age 18 were not be eligible to participate.

\subsection{Measures}

The survey consists of 10 background variables and three scales: the shortened Authoritarianism-Conservatism-Traditionalism (ACT) Scale (Duckitt, Bizumic, Krauss, Heled, 2010), the revised New Ecological Paradigm (NEP) Scale (Dunlap, Van Liere, Mertig, Jones, 2000), and the Pro-Environmental Behavior (PEB) Scale (Markle, 2013). All three scales were originally developed and tested with college students. Descriptive statistics can be found in tables 1,2 , and 3 .

\section{Dependent Variables}

The NEP measures individuals' pro-environmental beliefs by placing the dominant social paradigm in opposition of what Dunlap et al. has coined the 'New 
Ecological Paradigm' (2000). The New Ecological Paradigm scale (NEP) consists of 15 balanced statements, 3 statements for each of the five major facets of the New Ecological Paradigm (the belief that: the balance of nature is fragile, there are limits to growth, nature is valuable regardless of its resources, humanity cannot control nature through technology, and there is a possibly of an eco-crisis) (Dunlap et al., 2000). Respondents indicate how much they agree or disagree with each statement using a 5point Likert scale. Index scores are additive; answers to the 15 statements were summed, after reverse-scoring, giving a possible score range of $15-75$. A higher score indicates stronger pro-environmental attitudes. Descriptive statistics can be found in table 1. Dunlap et al. has found the scale to be highly internally consistent $(\alpha=0.83)$ (2000). A meta-analysis of 68 studies (140 total samples) found an average Cronbach's alpha of $\alpha=0.71$ across 36 countries and a variety of samples (Dunlap, 2008). The present study found the scale to be sufficiently internally consistent with a Cronbach's alpha of $\alpha=0.77$. Items were randomized within the index to address ordering bias. There is debate concerning whether the scale is unidimensional (Anderson, 2012; Atav et al., 2015). Dunlap addresses this directly, stating that he takes the belief-systems approach which views "the potential multidimensionality of the NEP not as a problem but as a means of documenting variation in the structure and coherence of an ecological worldview across cultures and among social strata in individual nations" and suggests that "researchers should use the Revised NEP Scale and then decide on the basis of their data analyses whether to treat it as a single or multidimensional scale" (Dunlap, 2008, pg. 13). The scale is treated as unidimensional in this research project due to insufficient 
$n$ counts determined by the subject to item ratio of 5:1 to carry out a factor analysis (Osborne \& Costello, 2004).

The PEB scale is based on the environment-first perspective, which posits the environmental impact of significant human behaviors, regardless of intention, responsible for compounding the most threatening environmental problems to humanity as the primary focus. Markle identified transportation-related activities, foodrelated activities, and household operation-related activities as the primary cause of the most threatening environmental problems: "air pollution, global warming, habitat alteration, and water pollution" (Markle, 2013, pg. 908). Markle also identified environmental citizenship behaviors due to its ability to influence public policy to create pro-environmental change. The PEB scale consists of 19 questions measured on a fivepoint scale with a variety of anchors that depend on the behavior being evaluated in each specific question. The index scores are created by summing the responses for the 19 questions together and range from 19 to 95 points. A higher score indicates practicing more pro-environmental behaviors. This scale was presented to respondents first in the survey to avoid any potential ordering bias caused by ruminating on values (i.e., mispresenting behaviors in order to present them as aligned more closely to beliefs). Descriptive statistics can be found in table 1 .

The investigators altered some questions in the PEB scale. Within the conservation subscale, three items were altered. "How often do you cut down on heating or air conditioning to limit energy use?" was altered to read "How often do you cut down on heating or air conditioning?" to broaden the reasons why one might cut 
down on temperature control, thus capturing a more valid assessment of habits that are more environmentally friendly, regardless of environmental intention. This question was measured on the original 5-point scale. "How often do you limit your time in the shower in order to conserve water?" was changed to "How many minutes do you typically spend showering?" to capture more accurately the environmental impact of the respondent's typical shower, regardless of the reason for the behavior. Data shows that on average, every two minutes spent showering uses enough energy to light an inefficient 60w compact fluorescent bulb for 12 hours (Maas, 2009). This was measured on a scale of: 5 minutes or less $=1,6-10$ minutes $=2,11-15$ minutes $=3,16-20$ minutes $=4,21$ minutes or more $=5$. This was reverse coded before analysis. "A mixedtemperature cycle" was added as a response option for the question "At which temperature do you wash most of your clothes?" to be more exhaustive. This was coded at a 3, the same as the response "warm".

Five items in the environmental citizenship subscale were altered. "Are you currently a member of any environmental, conservation, or wildlife protection group?" and "During the past year have you contributed money to an environmental, conservation, or wildlife protection group?" were both altered by adding "including recognized student organizations?" to the end of the question. This was added to ensure that the subjects taking it, who are university students, would include any universityrelated environmental protection group. "How frequently do you watch television programs, movies, or internet videos about environmental issues?" was altered; 'frequently' was changed to 'often' in order to match the scale. "During the past year 
have you increased the amount of organically grown fruits and vegetables you consume?" was altered to "In a typical week, how frequently do you eat organically grown fruits and vegetables?" in order to capture the environmental impact as-is, regardless of the intention for it. Respondents who have been, for example, vegetarians for the past 3 years might not have increased the amount they consume, and thus their data captured by the original question would misrepresent their environmental impact. This is scored as: Not at all $=1$, Once per week $=2$, a few times per week $=3$, once a day $=4$, more than once per day $=5$. This item is reverse coded. The item "Please answer the following question based on the vehicle you drive most often: approximately how many miles per gallon does the vehicle get?" was changed from 'approximately' to 'on average' to better account for the difference in mpg on the highway and in the city. "I do not drive any vehicles" was also added to be exhaustive and was coded as a 1 (this item is reverse scored).

In the food subscale, all 3 items were altered similarly to the organic fruits and vegetables item. The items read "During the past year have you decreased the amount of beef/pork/poultry you consume?", with a separate question for each meat type. The items were edited to "In a typical week, how frequently do you eat beef/pork/poultry?" in order to capture the environmental impact as-is and avoid any behavior misrepresentation for respondents who eat a low amount of meat for over a year. These are scored as: Not at all $=1$, Once per week $=2$, a few times per week $=3$, once a day $=$ 4 , more than once per day $=5$. These 3 items are reverse coded. Three items in the 
transportation subscale were altered; all three contained 'often' in the question, which was changed to 'frequently' in order to match the response options.

The present study set minimum alpha level at $\alpha=0.60$, due to the more exploratory nature of this study (Taber, 2018). The full-scale Cronbach's alpha is $\alpha=$ 0.61. 7 questions fall into the Conservation dimension $(\alpha=0.63), 6$ questions fall into the Environmental Citizenship dimension $(\alpha=0.46), 3$ fall into the Food dimension $(\alpha=$ 0.77), and the remaining 3 questions fall into the Transportation dimension ( $\alpha=0.53$ ) (Markle, 2013). Though some subscales have a lower-than-ideal internal consistency, it is important to remember that Cronbach's alpha is "very sensitive to the number of scale items" (Markle, 2013, pg. 910). All the PEB subscales have less than 10 items which commonly results in Cronbach values of 0.5 or less (Sirakaya-Turk, pg. 338). Other researchers have reported more internally consistent findings when examining the internal consistency of the full-scale or sub-scales (full-scale $\alpha=0.76$, conservation $\alpha=$ 0.74 , environmental citizenship $\alpha=0.65$, food $\alpha=0.66$, Markle, 2013; full-scale $\alpha=0.71$, Holmström, 2017; conservation scale $\alpha=0.70 \& \alpha=0.76$, composite reliability is $0.80 \&$ 0.84, Prati, Peitrantoni, \& Albanesi, 2017; transportation scale $\alpha=0.82$, Naderi, 2018).

\section{Table 1: Descriptive Statistics for Dependent Variables}

\begin{tabular}{|l|c|c|c|c|c|c|}
\hline & Frequency & Mean & Standard Deviation & Minimum & Maximum & Alpha \\
\hline NEP scale & 60 & 56.75 & 7.74 & 36 & 75 & 0.77 \\
\hline PEB scale & 60 & 59.83 & 7.50 & 42 & 75 & 0.61 \\
\hline
\end{tabular}

\section{Independent Variables}

The ACT scale is a 3-factor scale measuring right-wing authoritarianism. The 3 factors are authoritarianism (A scale), conservatism ( $\mathrm{C}$ scale), and traditionalism ( $\mathrm{T}$ 
scale). The shortened ACT scale, the form used in the present study, is comprised of 18 statements ( 9 reverse coded); each subscale consists of 6 statements ( 3 reverse coded). Each statement is evaluated on a 9-point Likert scale, coded from -4 to 4 . To assign whole-scale scores, the responses across all 18 items are added together and divided by the number of items, creating a possible score range of -4 to 4 . The subscale scores are computed by summing the responses up for the applicable 6 sub scale items and dividing by 6 , giving each subscale a range of -4 to 4 . A higher score indicates a moreright wing authoritarian mindset. Items were randomized within the whole index to prevent ordering bias. Descriptive statistics are given in table 2 . The present study reports full scale $\alpha=0.91$, A scale $\alpha=0.79$, C scale $\alpha=0.83$, and T scale $\alpha=0.87$, indicating the scale and subscales are reliable. Further research has demonstrated the reliability (full scale $\alpha=0.91$, A scale $\alpha=0.83$, C scale $\alpha=0.83$, T scale $\alpha=0.89$, Duckitt, Bizumic, Krauss, \& Heled, 2010; full scale $\alpha=0.88$, Devine-Wright, Price, \& Leviston, 2015; full scale $\alpha=0.84 \& \alpha=0.89$, Dunwoody \& Funke, 2016; full scale $\alpha=0.90$ and $\alpha=$ 0.92, Sinn \& Hayes, 2018; full scale $\alpha=0.87$, Bizumic \& Duckitt, 2018) and validity of this scale (Bizumic \& Duckitt, 2018).

\begin{tabular}{|l|c|c|c|c|c|c|}
\hline \multicolumn{7}{|l|}{ Table 2: Descriptive Statistics for Key Independent Variables } \\
\hline & Frequency & Mean & Standard Deviation & Minimum & Maximum & Alpha \\
\hline ACT scale & 57 & -1.35 & 1.39 & -3.9 & 1.5 & 0.91 \\
\hline A scale & 57 & -0.74 & 1.55 & -4.0 & 2.3 & 0.79 \\
\hline C scale & 57 & -1.51 & 1.68 & -4.0 & 2.0 & 0.83 \\
\hline T scale & 57 & -1.81 & 1.64 & -4.0 & 2.8 & 0.87 \\
\hline
\end{tabular}




\section{Background Variables}

The survey contains 8 background variables (table 3 ) used in the analyses. These variables include the following demographics: age, sex, race, and ethnicity. Age was coded as given by respondents. Item validation was utilized to ensure that answers over 100 would not be recorded and prompt the respondent to take a closer look at their response. Respondents were asked about their sex; options included male, female, trans male, trans female, nonbinary, or an 'another gender not listed here' category. Due to low $n$ categories, sex was coded male $=0$, female $=1$, and all other cases were dropped. When providing race, respondents had the option to choose 'white, 'black or African American', 'American Indian or Alaska Native', 'Asian', and 'another race not listed here'. Respondents were able to choose as many races as applied. Due to low $\mathrm{n}$ counts, categories were collapsed to 'white' or 'another race'. Ethnicity is measured by Hispanic or Non-Hispanic. Due to low $n$ categories (Hispanic: $n=4$ ), ethnicity was dropped from the analyses.

Other background variables include classification, housing type, political views, household income, academic major, and GPA. Respondents were asked the year they were classified as; 'first-year student', 'sophomore', 'junior', 'senior', and 'graduate student' were possible answers. To assess housing type, students were asked "During the academic year, which best describes your living situation?". Possible responses included 'campus dormitory', 'fraternity or sorority housing', 'campus-affiliated apartment', and 'off-campus residency'. Due to low n counts, campus dormitory and campus-affiliated housing were collapsed together to create the 'campus-affiliated' 
category. No respondents chose 'fraternity or sorority housing', and the category was not included in analyses. To assess political views, respondents were asked "Which most closely matches your political views?". Possible responses included 'Extremely conservative', 'Conservative', 'Slightly conservative', 'Moderate', 'Slightly liberal', 'Liberal', and 'Extremely liberal'. Due to low n counts, 'Extremely conservative', 'Conservative', and 'Slightly conservative' were collapsed into the category 'conservative'. 'Moderate' retained its original status. 'Slightly liberal', 'Liberal', and 'Extremely liberal' were collapsed into the 'liberal' category. Refer to Appendix A for a complete copy of the survey. GPA and income were dropped from analyses due to missing values and non-significance in analyses (income missing 15 observations; GPA missing 10 observations). Academic major was dropped from analyses due to low $\mathrm{n}$ categories. 


\begin{tabular}{|c|c|c|c|c|c|c|}
\hline Variable name & Frequency & $\%$ & Mean & Standard Deviation & Minimum & Maximum \\
\hline Age & 53 & & 22.87 & 7.29 & 18 & 49 \\
\hline \multicolumn{7}{|l|}{ Sex } \\
\hline Male* & 9 & $16.98 \%$ & & & & \\
\hline Female & 44 & $83.02 \%$ & & & & \\
\hline \multicolumn{7}{|l|}{ Race } \\
\hline White* & 44 & $83.02 \%$ & & & & \\
\hline $\begin{array}{l}\text { Identification } \\
\text { other than } \\
\text { white } \\
\end{array}$ & 9 & $16.98 \%$ & & & & \\
\hline \multicolumn{7}{|l|}{ Classification (in School) } \\
\hline First year & 18 & $33.96 \%$ & & & & \\
\hline Sophomore & 10 & $18.87 \%$ & & & & \\
\hline Junior & 17 & $32.08 \%$ & & & & \\
\hline Senior & 7 & $13.21 \%$ & & & & \\
\hline Graduate & 1 & $1.89 \%$ & & & & \\
\hline \multicolumn{7}{|l|}{ Political Views } \\
\hline Conservative & 7 & $13.21 \%$ & & & & \\
\hline Moderate & 16 & $30.19 \%$ & & & & \\
\hline Liberal & 30 & $56.60 \%$ & & & & \\
\hline \multicolumn{7}{|l|}{ Housing } \\
\hline $\begin{array}{l}\text { Campus } \\
\text { Affiliated* }\end{array}$ & 16 & $30.19 \%$ & & & & \\
\hline Off Campus & 37 & $69.81 \%$ & & & & \\
\hline
\end{tabular}

\subsection{Analysis}

The researcher examined 4 questions.

- 1 . Does the degree to which one has right-wing authoritarian social attitudes relate to the degree to which one holds pro-environmental beliefs?

- 2. Does the degree to which one has right-wing authoritarian social attitudes relate to the degree to which one practices pro-environmental behaviors?

- 3. Of the 3 dimensions that make up right-wing authoritarianism, do any relate with people's pro-environmental beliefs? 
- 4. Of the 3 dimensions that make up right-wing authoritarianism, do any relate with people's pro-environmental behaviors?

To examine these questions, the researcher employed multiple linear regression. This is the most appropriate type of analysis for the data as the investigators are interested in relationships and the dependent variables (pro-environmental beliefs and behaviors) are both interval-level variables. All analyses were carried out using Stata SE 16.1. Multiple linear regression tests the relationship between an independent and dependent variable (regression coefficient), whether this relationship is statistically significant from no relationship ( $p$-value), and how much of the variance in the dependent variable can be explained by the model $\left(R^{2}\right)$. Due to the exploratory nature of this study, minimum significant $p$ levels were set to $p=0.10$. For increased interpretability of the intercept coefficient in the regression models, interval/ratio variables were centered on the mean and ordinal and nominal level variables were centered on the mode. Background variables will serve as controls for the planned analyses. These analyses were carried out initially without controlling for background variables, and then reanalyzed to include the background variables as controls. Respondents that were not missing data for the NEP, PEB, or ACT scales were included in the analyses without controls. Casewise deletion was used to run regression analyses $(n=53)$. 


\section{RESULTS}

This section reviews the multiple linear regression analyses modeling authoritarian theory for both pro-environmental beliefs and pro-environmental behaviors. Table 4 displays the zero-order correlations of all variables for all complete observations. As is expected, the ACT scale and the A, C, and T subscales are very strongly correlated; these correlations are highly significant. This further reinforces the reliability of the ACT scale and subscales. Political views have a strong and significant correlation to ACT as expected from the literature, providing criterion validity. Political views are also strongly correlated to the $\mathrm{C}$ and $\mathrm{T}$ subscales, but only moderately correlated to the A subscale (all correlations are highly significant). The ACT and subscales have a moderate significant negative correlation to NEP scores. The ACT scale has a moderate significant negative correlation to PEB scores, and the A, C, and T subscales are weakly, but significantly, negatively correlated to PEB scores. Political views are significantly moderately correlated to NEP scores, but weakly correlated to PEB scores (both are significant). NEP and PEB scores are significantly moderately correlated. 


\begin{tabular}{|c|c|c|c|c|c|c|c|c|c|c|c|c|}
\hline & NEP & PEB & ACT & A scale & C scale & T scale & Race & Age & Housing & $\begin{array}{c}\text { Political } \\
\text { Views }\end{array}$ & Sex & $\begin{array}{l}\text { Classifi- } \\
\text { cation }\end{array}$ \\
\hline NEP & 1.000 & & & & & & & & & & & \\
\hline PEB & $\begin{array}{c}0.430^{4} \\
* *\end{array}$ & 1.000 & & & & & & & & & & \\
\hline ACT & $\begin{array}{c}-0.444^{4} \\
* * *\end{array}$ & $\begin{array}{c}-0.421^{4} \\
* *\end{array}$ & 1.000 & & & & & & & & & \\
\hline A scale & $\begin{array}{c}-0.323^{4} \\
*\end{array}$ & $\begin{array}{c}-0.350^{4} \\
*\end{array}$ & $\begin{array}{c}0.835^{4} \\
* * *\end{array}$ & 1.000 & & & & & & & & \\
\hline C scale & $\begin{array}{c}-0.374^{4} \\
* *\end{array}$ & $\begin{array}{c}-0.381^{4} \\
* *\end{array}$ & $\begin{array}{c}0.918^{4} \\
* * *\end{array}$ & $\begin{array}{c}0.718^{4} \\
* * *\end{array}$ & 1.000 & & & & & & & \\
\hline T scale & $\begin{array}{c}-0.439^{4} \\
* *\end{array}$ & $\begin{array}{c}-0.350^{4} \\
*\end{array}$ & $\begin{array}{c}0.811^{4} \\
* * *\end{array}$ & $\begin{array}{c}0.441^{4} \\
* * *\end{array}$ & $\begin{array}{c}0.628^{4} \\
* * *\end{array}$ & 1.000 & & & & & & \\
\hline Race & $0.018^{5}$ & $-0.008^{5}$ & $0.146^{5}$ & $0.026^{5}$ & $0.067^{5}$ & $\begin{array}{c}0.279^{5} \\
*\end{array}$ & 1.000 & & & & & \\
\hline Age & $0.203^{4}$ & $-0.119^{4}$ & $-0.103^{4}$ & $-0.150^{4}$ & $-0.058^{4}$ & $-0.060^{4}$ & $-0.040^{5}$ & 1.000 & & & & \\
\hline Housing & $0.176^{5}$ & $0.006^{5}$ & $0.016^{5}$ & $0.062^{5}$ & $0.071^{5}$ & $-0.091^{5}$ & $0.232^{2}$ & $\begin{array}{c}0.304^{5} \\
*\end{array}$ & 1.000 & & & \\
\hline $\begin{array}{l}\text { Political } \\
\text { Views }\end{array}$ & $\begin{array}{c}0.456^{3} \\
* * * \\
\end{array}$ & $\begin{array}{c}0.271^{3} \\
*\end{array}$ & $\begin{array}{c}-0.738^{3} \\
* * *\end{array}$ & $\begin{array}{c}-0.497^{3} \\
* * *\end{array}$ & $\begin{array}{c}-0.677^{3} \\
* * *\end{array}$ & $\begin{array}{c}-0.736^{3} \\
* * *\end{array}$ & $0.276^{2}$ & $0.083^{3}$ & $0.076^{2}$ & 1.000 & & \\
\hline Sex & $0.157^{5}$ & $-0.031^{5}$ & $0.119^{5}$ & $-0.096^{5}$ & $0.192^{5}$ & $0.197^{5}$ & $0.071^{2}$ & $-0.029^{5}$ & $-0.108^{2}$ & $-0.093^{2}$ & 1.000 & \\
\hline Classification & $\begin{array}{c}0.352^{3} \\
* *\end{array}$ & $0.190^{3}$ & $\begin{array}{c}-0.252^{3} \\
\circ\end{array}$ & $\begin{array}{c}-0.235^{3} \\
0\end{array}$ & $-0.235^{3}$ & $-0.262^{3}$ & $0.363^{2}$ & $\begin{array}{c}0.714^{3} \\
* * * \\
\end{array}$ & $\begin{array}{c}0.622^{2} \\
* * * \\
\end{array}$ & $0.171^{3}$ & $0.287^{2}$ & 1.000 \\
\hline \multicolumn{13}{|c|}{$\begin{array}{l}{ }_{1}^{1} \mathrm{n}=53,{ }^{\circ} \mathrm{p}<0.1 ; * \mathrm{p}<0.05 ; * * \mathrm{p}<0.01 ; * * * \mathrm{p}<0.001 \\
{ }^{2} \text { Cramer's } \mathrm{V} \\
{ }^{3} \text { Spearman rank correlation } \\
{ }^{4} \text { Pearson's correlation coefficient } \\
{ }^{5} \text { biserial correlation }\end{array}$} \\
\hline
\end{tabular}




\subsection{Environmental Beliefs}

Models 1 - 5 (table 5) employ linear regression modeling the correlations between the ACT, A, C, T and A-C-T subscales to the NEP scale. For each model, all multiple regression assumptions were checked. Collinearity was assessed for each model by checking the variance inflation factors (VIF). VIFs of above 5 are generally considered to indicate strong collinearity, while VIFs of 10 or larger are regarded as indicative of extremely high collinearity (Hill \& Adkins, 2001). VIFs were checked and none were found to be above 5 in any of the models. Checks for outliers were assessed in each model by obtaining the critical value and comparing the absolute value to the studentized deviance residuals. No outliers were found in any of the models. Skew was checked for all independent interval-ratio variables; age was found to have a significant positive skew and thus was transformed age $\mathrm{e}^{-4}$ to correct skew in all analyses.

For each model, the dependent variable was assessed for heteroscedasticity and non-normality. The Breusch-Pagan test was carried out; the null of this test assumes the regression residuals are homoscedastic. No issues were found, and NEP scores were declared homoscedastic. The regression residuals were then assessed for normality, which occurs when the regression residuals are not normally distributed. Four tests were employed to assess normality: the Shapiro-Wilk test, the Shapiro-Francia test, the skewness statistic, and the kurtosis statistic. No dependent variable issues were found, and NEP scores were considered approximately normally distributed. 
The multiple regressions for models 1-5 were then carried out. Due to the exploratory nature of the study, a backwards stepwise regression selection method was employed on control variables to in order to examine statistically significant correlations at the $p=0.100$ level. The backwards selection method removes variables insignificant at a pre-specified level ( $p=0.100$ in the present study) one by one in order of descending significance. After a variable is removed, the model is reassessed for changes in significance, and the next variables with the largest $p$-value is dropped. This is done until all remaining variables are declared significant. Variables can be excluded from the selection process, ensuring they remain in the model despite their $p$-values; independent variables of interest in the present study were excluded from the backwards selection technique. Adjusted $R^{2}$ from the initial and final models were compared to ensure backwards selection resulted in a better model fit. Table 5 displays the analyses results. 


\begin{tabular}{|c|c|c|c|c|c|}
\hline & Model 1 & Model 2 & Model 3 & Model 4 & Model 5 \\
\hline ACT scale & $\begin{array}{c}-2.200 * * \\
(-3.336,-1.064)\end{array}$ & & & & \\
\hline A scale & & $\begin{array}{c}-0.046 \\
(-0.234,0.143) \\
\end{array}$ & & & $\begin{array}{c}0.421 \\
(-1.086,1.927) \\
\end{array}$ \\
\hline C scale & & & $\begin{array}{c}-0.106 \\
(-0.314,0.101)\end{array}$ & & $\begin{array}{c}-0.986 \\
(-2.530,0.557)\end{array}$ \\
\hline T scale & & & & $\begin{array}{c}-2.009 * * * \\
(-2.949,-1.067) \\
\end{array}$ & $\begin{array}{c}-1.580^{*} \\
(-2.763,-0.398) \\
\end{array}$ \\
\hline Sex $($ Female $=1)$ & $\begin{array}{c}4.746^{\circ} \\
(0.710,8.782)\end{array}$ & $\begin{array}{c}4.304^{\circ} \\
(0.219,8.389)\end{array}$ & $\begin{array}{c}4.857^{*} \\
(0.797,8.918)\end{array}$ & $\begin{array}{c}5.574^{*} \\
(1.567,9.582) \\
\end{array}$ & $\begin{array}{c}6.212^{*} \\
(1.853,10.571)\end{array}$ \\
\hline Classification & $\begin{array}{c}1.491^{\circ} \\
(0.099,2.884) \\
\end{array}$ & $\begin{array}{c}1.568^{\circ} \\
(0.164,2.971) \\
\end{array}$ & $\begin{array}{c}1.575^{\circ} \\
(0.209,2.941) \\
\end{array}$ & $\begin{array}{c}1.654^{*} \\
(0.311,2.996) \\
\end{array}$ & $\begin{array}{c}1.637^{\circ} \\
(0.245,3.030)\end{array}$ \\
\hline Political Views & & $\begin{array}{c}4.109^{* *} \\
(1.735,6.482) \\
\end{array}$ & $\begin{array}{c}3.386^{\circ} \\
(0.539,6.234) \\
\end{array}$ & & \\
\hline Constant & $\begin{array}{c}55.789 * * * \\
(53.403,58.175)\end{array}$ & $\begin{array}{c}57.940 * * * \\
(55.104,60.776)\end{array}$ & $\begin{array}{c}57.615^{* * *} \\
(54.129,61.102)\end{array}$ & $\begin{array}{c}55.718^{* * *} \\
(53.392,58.044)\end{array}$ & $\begin{array}{c}55.848^{* * *} \\
(53.485 \\
58.210)\end{array}$ \\
\hline $\mathrm{R}^{2}$ & 0.289 & 0.307 & 0.315 & 0.315 & 0.333 \\
\hline \multicolumn{6}{|c|}{$\begin{array}{l}{ }_{1} \text { Coefficients are unstandardized. }{ }^{\circ} \mathrm{p}<0.1 ; * \mathrm{p}<0.05 ; * * \mathrm{p}<0.01 ; * * * \mathrm{p}<0.001 .90 \% \text { Cis are in parenthesis. ACT, A, C, and T scales } \\
\text { were excluded from backwards selection. Blank control variable cells indicate insignificant } \mathrm{p} \text {-values at the } \mathrm{p}=0.100 \text { level and those } \\
\text { variables were excluded from the final model. Missing control variables insignificant } \mathrm{p} \text {-values at the } p=0.100 \text { level and those variables } \\
\text { were excluded from all final models. Blank independent variable cells indicate that scale was not used in the model. }\end{array}$} \\
\hline
\end{tabular}

Model 1 displays the results of regressing NEP scores on ACT scale scores (table 5). A backwards selection approach was used to determine variables of significant correlation to NEP scale. Sex $(p=0.054)$, classification $(p=0.079)$, and ACT scale $(p=$ 0.002 ) are all found to be significantly related with NEP score. The constant can be interpreted to the average respondent; a female first year student who does not live in a dormitory has an average NEP score of about 56 points. The independent variable of interest, ACT score, is negatively related to NEP score by an average -2.2 points, meaning that every additional ACT scale point (or the more authoritarian one is) is associated with an average decrease in NEP score (the less pro-environmental a respondent's beliefs about the environment are) by 2 points. On average, women's NEP scores are about 5 points higher than men's scores, and every additional year of 
classification is related to an increase in NEP score by 1.5 points. Model 1 has an $\mathrm{R}^{2}=$ 0.30, meaning about $30 \%$ of the variation in NEP scores can be explained by this model. By comparing the adjusted $R^{2}$ of model 1 (adjusted $R^{2}=0.246$ ) to the adjusted $R^{2}$ of model 1 without the ACT scale (adjusted $R^{2}=0.102$ ), the explanatory power the inclusion of the ACT scale adds to model 1's ability to explain the variance in NEP scores is high. A one standard deviation increase in the ACT scale $(\beta=-0.41)$ is associated with more than double the change in NEP scores compared to a one standard deviation increase in sex $(\beta=0.24)$ (men are the reference category) and a one standard deviation increase in classification $(\beta=0.23)$.

Model 2 displays the results regressing just the A scale on NEP scores, and model 3 displays the results regressing just the $C$ scale on NEP scores (table 5 ). Recall that the variables of interest, the authoritarian scales, were excluded from selection when performing backwards selection. Neither the A $(p=0.687)$ nor the C scale $(p=0.394)$ were found to be significantly related to NEP scores. Sex (model 2: $p=0.084$, model 3: $p$ $=0.050$ ), classification (model $2: p=0.067$, model 3: $p=0.059$ ), and political views (model 2: $p=0.006$, model $3: p=0.052$ ) were found to be significantly related to NEP scores. Model 2 explains about 31\% of the variance in NEP scores, but when the adjusted $R^{2}$ of model 2 (adjusted $R^{2}=0.249$ ) is compared to the adjusted $R^{2}$ of the model excluding A scale (adjusted $R^{2}=0.262$ ), it is clear that the A scale detracts from the model's ability to explain the variance of NEP scores. The beta coefficients indicate that political views $(\beta=0.40)$ largely drive the explanatory power of model 2 while the $A$ scale $(\beta=-0.06)$ explains very little. Model $3\left(R^{2}=0.32\right)$ explains about $32 \%$ of the 
variance in NEP scores. Looking at model 3, the model's adjusted $R^{2}=0.258$, but when the key independent variable $C$ scale is not included, the adjusted $R^{2}=0.262$, indicating that the inclusion of the $\mathrm{C}$ scale slightly decreases the model's explanatory power of NEP scores. When analyzing the beta coefficients of model 3, a one standard deviation increase in political views $(\beta=0.33)$ is about twice as effective in explaining NEP scores as a one standard deviation in C scale score $(\beta=-0.14)$.

Model 4 models the relationship between the T scale and NEP scores when regressing NEP scores on the T scale. The T scale was found to have a significantly negative relationship with NEP scores $(p=0.001)$. Sex $(p=0.024)$ and classification $(p=$ 0.044 ) also relate significantly with NEP scores. Women average nearly 6 points higher than men on the NEP scale, and each additional classification in college typically increases NEP scores by almost 2 points. Model 4 has an adjusted $R^{2}=0.273$, which is larger compared to the model excluding the $T$ scale (adjusted $R^{2}=0.102$ ) indicating the inclusion, rather than the exclusion, of the T scale in provides a much stronger association with NEP scores. The T scale $(\beta=-0.44)$ has greater explanatory power than sex $(\beta=0.28)$ or classification $(\beta=0.25)$. This model accounts for nearly $32 \%$ of the variation in NEP scores.

In the final model, model 5, the A, C, and T scales are tested to further discern any subscales primarily driving the results of the ACT scale in model 1 . Only the T scale $(p=0.030)$ significantly relates with the NEP score. For each additional point increase in the T scale, NEP score decreases by an average of -1.6 points. The $A$ and $C$ scales, as in models 2 and 3, remain insignificant $(A-p=0.642, C-p=0.289)$. Of the control variables, 
sex $(p=0.021)$ and classification $(p=0.054)$ once again are shown to be significantly related to NEP scores. Female students average about 6 points higher on the NEP scale when compared to men, and each additional classification results of an average increase of about 2 points in NEP scale score. Although this model explains about $33 \%$ of the variance in NEP score (the largest $R^{2}$ of the 5 models), when comparing the adjusted $R^{2}$ between model 5 (adjusted $R^{2}=0.262$ ), a model without the 3 key variables of interest (adjusted $R^{2}=0.102$ ), and a model with only the $T$ scale included (the only subscale with a significant association) (adjusted $\mathrm{R}^{2}=0.273$ ), it becomes clear that the model with only the T score has the most powerful association with NEP scores. This is the same model tested in model 4 , indicating it fits slightly better than model 5 . The beta coefficients are as follows: $A$ scale $\beta=0.09, C$ scale $\beta=-0.22$, T scale $\beta=-0.35$, sex $\beta=$ 0.32 , classification $\beta=0.25$. A one standard deviation in the $T$ scale has the strongest association to NEP scores.

\subsection{Environmental Behaviors}

Models $1-5$ (table 6) employ multiple stepwise regressions modeling the relationships of the ACT, A, C, T and A-C-T subscales to the PEB scale. For each model, all multiple regression assumptions were checked using the same tests outlined in Results 1.2 NEP section. VIFs were checked to assess collinearity, and none were found to be above 5 in any of the models. No outliers were found in any of the models when comparing the absolute value of the critical value to the studentized deviance residuals. Age was found to have a significant positive skew and thus was transformed age ${ }^{-4}$ to correct skew in all analyses. 
For each model, the dependent variable was assessed for heteroscedasticity and non-normality. Heteroscedasticity was assessed using the Breusch-Pagan test, and PEB scores were declared homoscedastic. The regression residuals were then assessed for normality using the Shapiro-Wilk test, the Shapiro-Francia test, the skewness statistic, and the kurtosis statistic. No normality issues were found, and PEB scores were declared normally distributed.

Due to the exploratory nature of the study, a backwards stepwise regression selection method was employed on control variables to in order to examine statistically significant correlations at the $p=0.100$ level. Adjusted $R^{2}$ from the initial and final models were compared to ensure backwards selection resulted in a better model fit. Table 6 displays the analyses results.

\begin{tabular}{|c|c|c|c|c|c|}
\hline & Model 1 & Model 2 & Model 3 & Model 4 & Model 5 \\
\hline ACT scale & $\begin{array}{c}-2.152^{* *} \\
(-3.319,-0.985)\end{array}$ & & & & \\
\hline A scale & & $\begin{array}{c}-1.586^{*} \\
(-2.658,-0.513)\end{array}$ & & & $\begin{array}{c}-0.682 \\
(-2.171,0.806)\end{array}$ \\
\hline C scale & & & $\begin{array}{c}-1.632 * * \\
(-2.594,-0.670) \\
\end{array}$ & & $\begin{array}{c}-0.830 \\
(-2.396,0.736)\end{array}$ \\
\hline T scale & & & & $\begin{array}{c}-1.397^{*} \\
(-2.411,-0.384)\end{array}$ & $\begin{array}{c}-0.618 \\
(-1.877,0.640)\end{array}$ \\
\hline Classification & $\begin{array}{c}2.526^{*} \\
(0.636,4.417) \\
\end{array}$ & $\begin{array}{c}2.752^{*} \\
(0.816,4.688) \\
\end{array}$ & $\begin{array}{c}2.793^{*} \\
(0.906,4.680) \\
\end{array}$ & $\begin{array}{c}2.794^{*} \\
(0.845,4.744) \\
\end{array}$ & $\begin{array}{c}2.542^{*} \\
(0.600,4.483) \\
\end{array}$ \\
\hline $\mathrm{Age}^{2}$ & $\begin{array}{c}1247100 * * \\
(542129.7 \\
1952070)\end{array}$ & $\begin{array}{c}1291220 * * \\
(565794.6, \\
2016646)\end{array}$ & $\begin{array}{c}1298603^{* *} \\
(585882.5 \\
2011324)\end{array}$ & $\begin{array}{c}1229885^{* *} \\
(496005 \\
1963766)\end{array}$ & $\begin{array}{c}1252892^{* *} \\
(529579.9 \\
1976204)\end{array}$ \\
\hline Constant & $\begin{array}{c}57.070 * * * \\
(54.168,59.971)\end{array}$ & $\begin{array}{c}56.776 * * * \\
(53.799,59.752)\end{array}$ & $\begin{array}{c}56.722 * * * \\
(53.814,59.630)\end{array}$ & $\begin{array}{c}56.721 * * * \\
(53.723,59.718)\end{array}$ & $\begin{array}{c}57.049 * * * \\
(54.074,60.025)\end{array}$ \\
\hline $\mathrm{R}^{2}$ & 0.305 & 0.262 & 0.287 & 0.251 & 0.305 \\
\hline \multicolumn{6}{|c|}{$\begin{array}{l}{ }^{1} \text { Coefficients are unstandardized. }{ }^{\circ} p<0.1 ; * p<0.05 ; * * p<0.01 ; * * * p<0.001 .90 \% \text { Cis are in parenthesis. ACT, A, C, and T } \\
\text { scales were excluded from backwards selection. Blank control variable cells indicate insignificant } p \text {-values at the } p=0.100 \\
\text { level and those variables were excluded from the final model. Missing control variables insignificant } p \text {-values at the } p=0.100 \\
\text { level and those variables were excluded from all final models. Blank independent variable cells indicate that scale was not } \\
\text { used in the model. } \\
{ }^{2} \text { Age transformed Age }{ }^{-4} \text { to correct skew and linearity }\end{array}$} \\
\hline
\end{tabular}


Model 1 presents the results of regressing PEB scores on ACT scale scores (table 6). A backwards selection approach was used to determine control variables significantly related to PEB scores. The constant is interpreted to the average PEB score of about 57 points for a respondent who is about 23 years old and a first-year student. The ACT scale $(p=0.003)$ has a significantly negative relationship to PEB scores, meaning every onepoint increase in a student's ACT score (i.e., the more authoritarian one is) is associated with an average decrease of about 2 points in their PEB score (i.e., the less environmentally friendly their behaviors are). Of the control variables, two are significant: classification $(p=0.030)$ and the fourth root of age $(p=0.005)$. Both are positively associated, meaning an increase in classification and/or an increase in age is associated with a positive increase in PEB scores. Model 1 has an $\mathrm{R}^{2}=0.31$, meaning about $31 \%$ of the variation in PEB scores can be explained by the ACT scale. By comparing adjusted $R^{2}$ of model 1 (adjusted $R^{2}=0.262$ ) to the adjusted $R^{2}$ of the model without the key independent variables (adjusted $R^{2}=0.136$ ), it becomes evident that model 1 is stronger with the ACT scale than without. The beta coefficients ( $\beta_{\text {ACT scale }}=-$ $\left.0.38, \beta_{\text {age }}=0.47, \beta_{\text {classification }}=0.37\right)$ indicate that, of those variables, age relates the strongest with PEB scores, and the ACT scale and classification are both related with PEB scores about as strongly.

Model 2 (table 6) displays the results regressing the A scale on PEB scores. The A scale is significantly negatively related with PEB scores; for every one-point increase in the A scale, respondents generally experience a 1.6-point decrease in their PEB score ( $p$ 
$=0.017$ ). In other words, the more authoritarian (the subscale authoritarianism, not to be confused with the larger concept of right-wing authoritarianism) a student is, the less environmentally friendly their behaviors are. Model 3 displays the results regressing just the $\mathrm{C}$ scale on PEB scores. The $\mathrm{C}$ scale is significantly associated with an average decrease of about 1.6 points in PEB score for every one-point increase in the $C$ scale $(p=$ 0.006). Model 4 displays the results of regressing PEB scores on the T scale. The T scale is significantly $(p=0.025)$ negatively related with PEB scores; every one-point increase in the T scale is associated with a decrease in PEB score of about -1.4 points, meaning the more traditional one is, the less environmentally friendly their behaviors are. In models 2,3 , and 4, classification (model 2: $p=0.021$, model 3: $p=0.017$, model 4: $p=0.020$ ) and the fourth root of age (model 2: $p=0.004$, model $3: p=0.006$, model $4: p=0.007$ ) also significantly correlate to the PEB scale in this model.

Model 2, 3, and 4 explain 26\%, 29\%, and 25\% of the variance in PEB scores respectively. The adjusted $R^{2}$ of model 2 (adjusted $\left.R^{2}=0.216\right)$, model $3\left(\right.$ adjusted $R^{2}=$ 0.243 ), and model 4 (adjusted $R^{2}=0.205$ ) compared to the adjusted $R^{2}$ of these models excluding the key independent variable (model 2: the A scale, model 3: the C scale, model 4: the T scale) $\left(R^{2}=0.136\right)$ indicates that the addition of the $A$ scale, the $C$ scale, and the T scale to their respective models results in a greater ability in each to explain the variance in PEB scores. Although the A scale (model 2) is a significant, the beta coefficients $\left(\beta_{\text {A scale }}=-0.32, \beta_{\text {age }}=0.49, \beta_{\text {classification }}=0.40\right)$ indicate that an increase of one standard deviation in age associates with PEB scores about 1.5 times stronger than a one standard deviation increase in the A scale, and a one standard deviation increase in 
classification associates with PEB scores about 1.25 stronger than a one standard deviation increase in the A scale. Model 3's beta coefficients $\left(\beta_{\text {c scale }}=-0.35, \beta_{\text {age }}=0.49\right.$, $\left.\beta_{\text {classification }}=0.41\right)$ show a very similar pattern to model 2 . The beta coefficients of model 4 follow a similar pattern as well; $\beta_{\text {T scale }}=-0.29, \beta_{\text {age }}=0.47, \beta_{\text {classification }}=0.41$. Age is about 1.6 times and classification is about 1.4 times as strongly associated with PEB scores compared to the T scale. While all three variables in each model are significantly associated with PEB scores, both age and association are more strongly associated PEB scores than the $A, C$, and $T$ scales.

Model 5 presents the results of regressing PEB scores on the A, C, and T scales. Neither the A, C, nor T scales are significant when controlling for the others. As with models $1-4$, classification $(p=0.033)$ and the fourth root of age $(p=0.006)$ are significantly associated with PEB scores. This model explains about $31 \%$ of the variance in PEB score, indicating the model fit between model 1 and model 5 are about comparatively about the same. When looking at the adjusted $R^{2}$ of model 5 (adjusted $R^{2}$ $=0.231)$ versus the adjusted $R^{2}$ of the model without the key independent variables (adjusted $\mathrm{R}^{2}=0.136$ ), it appears that including each of the three subscales in the model explains more of the variation in PEB scores than without. However, when this is compared to model 1 (adjusted $\mathrm{R}^{2}=0.262$ ), it becomes clear that model 1 models the association between authoritarianism more strongly than model 5. Model 1 is the best fitting model of the two.

Finally, as a robustness check all relationships modelled in tables 5 and 6 were assessed as nonlinear models. Relationships were modelled in fractional polynomial 
models and piecewise regression models; initial piecewise regression models modeled two and three splines (knots placed at the $50^{\text {th }}$ percentile, $33^{\text {rd }}$ and $66^{\text {th }}$ percentiles respectively). The linear models modelled in table 6 fit the best, indicating that the relationships between authoritarianism and pro-environmental behaviors are linear. While the fractional polynomial models modelling the relationship between NEP scores and authoritarianism did not fit better, piecewise regression models fit the ACT-NEP and the C-NEP models better. The A-NEP and T-NEP relationships were modelled best using a multiple regression. The three-spline ACT scale appeared to fit best of the initial models tested. Further investigation indicated that there was not a significant difference in the slopes of splines 1 and 2, and they were thus combined into one spline. A piecewise regression regressing environmental beliefs on 2 ACT scale splines was conducted with the first spline containing the bottom $66 \%$ of ACT scores (scores up to and including -0.31 ) and the second spline containing the top 33\% of ACT scores (scores above -0.31$)$. The slope of the first spline $(\beta=-0.97, p=0.307)$ was not significantly different from 0 indicating that for respondents who scored in the bottom $66 \%$ of the ACT scale scores, their ACT score, or overall level of authoritarianism, is not significantly related to the NEP score, or pro-environmental beliefs. The second spline has a significant slope $(\beta=-8.05, p=0.002)$ when compared to a slope of 0 and does significantly differ from the slope of the first spline $(p=0.014)$. Using a backwards stepwise regression selection method, sex remained significantly related $(\beta=4.79, p=$ 0.041 ) to NEP scores, while classification did not when comparing table 5 , model 1 to this 2-spline model. Housing emerged as being significantly related ( $\beta=4.18, p=0.029$ ) 
to NEP scores. $\mathrm{R}^{2}=0.37$, indicating this is a better fitting model than the linear regression model modeled in table 5.

The 3 spline $C$ scale appeared to fit better than the initial 2 spline model. Further investigation indicated the slopes of splines 1 and 2 were not significantly different from each other, and they were thus combined into a single spline. A piecewise regression regressing environmental beliefs on the $2 \mathrm{C}$ scale splines was conducted with the first spline containing the bottom $66 \%$ of $C$ scale scores and the second spline containing the top 33\% of $C$ scale scores. The slope of the first spline $(\beta=0.39, p=0.685)$ was not significantly different from 0 indicating that for respondents who scored in the bottom $66 \%$ of the C scale scores, their C scale score is not significantly related to the NEP score, or pro-environmental beliefs. The second spline has a significant slope $(\beta=-4.25, p=$ 0.070) when compared to a slope of 0 and is significantly different from the slope of the first spline $(p=0.066)$. Using a backwards stepwise regression selection method, sex $(\beta=$ 4.64, $p=0.057)$, classification $(\beta=1.78, p=0.033)$, and political views $(\beta=3.28, p=$ 0.056 ) all positively and significantly related to NEP scores, as modeled in table 5 , model 3. $R^{2}=0.353$, indicating this is a better fitting model than the corresponding linear regression model. Due to a low number of responses $(n=53)$, the spline models have limited statistical power. 


\section{DISCUSSION}

The present study suggests that environmental beliefs and environmental behaviors are related negatively to authoritarianism. Recall that right-wing authoritarianism encompasses the idea that in order to achieve and maintain society's collective security from social threat, individuals must subordinate themselves to collective authority (Duckitt et al., 2010). The NEP scale measures environmental beliefs and associates them closer to the Dominant Social Paradigm or closer to the New Ecological Paradigm. Recall the five overarching environmental beliefs that constitute the Dominant Social Paradigm: the balance of nature is resilient to human interference, economic growth is limitless, nature is valuable only insofar that it provides humanity resources, humanity will learn how to control nature, and that a major eco-crisis occurring is extremely implausible and perhaps even impossible (Dunlap et al., 2003). This relationship suggests that the more authoritarian one is, the more likely they are to hold a worldview in line with the Dominant Social Paradigm. The negative relationship found between environmental beliefs and authoritarianism conforms with past research (Schultz and Stone, 1994; Devine-Wright et al., 2015; Stanley and Wilson, 2019). The negative relationship found between authoritarianism and pro-environmental behaviors supports the relationship Altemeyer observed in his 1996 and 2003 qualitative studies. 
This study explored these relationships further by examining them at the subscale level. At this time of this study, there does not appear to be any research examining the relationship between environmental beliefs as measured by the NEP scale and authoritarianism at the sub-scale level as measured by the ACT scale. Recall that right-wing authoritarianism is made of three dimensions that each represent a specific method of achieving and maintaining this collective security (Duckitt et al., 2010). The present study found that only one particular method, or dimension, was related (negatively) to environmental beliefs: traditionalism (the T subscale). Authoritarian traditionalists seek to attain and maintain traditional lifestyles through "resisting 'modern' liberal, secular, open, lifestyles, norms, and morality" (Duckitt et al., 2010, pg. 691). They view these 'modern' social changes as individuals rejecting values set by collective authorities, which introduces uncertainty of social values into society. Traditionalists attribute society's keeping of traditional lifestyles as a method of ensuring collective societal security. Traditionalism is also related negatively with proenvironmental behaviors.

At the sub-scale level, in addition to traditionalism, authoritarianism (A subscale) and conservatism (c subscale) both significantly related negatively with proenvironmental behaviors. Recall that authoritarianism describes a preference of using harsh punishments and "coercive social control" in response to breaches of social rules and laws; authoritarians (as defined by the subscale, not to be confused with the broader term) fear physical threats or attacks to society's security and consider coercive social control the best method of deterring attacks and mitigating risks to the collective 
security of society (Duckitt et al., 2010, pg. 690). Conservatives fear threats to the unity of society and embody attitudes that support obedience and respect to the dominant social institutions and authorities in society (Duckitt et al., 2010). Thus, they value upholding the status quo and unquestioning submission to society's authorities as a method of ensuring collective security.

\subsection{Environmental Beliefs}

The Dominant Social Paradigm stems directly from the traditional values the United States was founded on; for example, exemptionalism can be traced to Adam Smith (Shafer, 2006). As the DSP is comprised of traditionalist beliefs, it easy to see why a negative relationship exists between the NEP and authoritarian traditionalists. The NEP is a direct affront to the long standing, traditional values that traditionalists believe holds society intact (Shafer, 2006). Anti-anthropocentrism, for instance, contradicts the traditional Christian value that man was divinely granted dominion over nature, which is the basis of anthropocentrism (Shafer, 2006). The NEP's 'modern' values are seen as a threat to the collective security of society because they introduce the idea that the DSP, or traditionalist values, are no longer useful to society. As a response to the perceived threat, traditionalists have rejected the NEP in favor of the DSP.

The present study found no evidence that possessing any level of authoritarian (A subscale) or authoritarian conservative values impacted environmental beliefs, or endorsement of the NEP. The most likely reason for this is that authoritarians (A subscale) are not concerned with environmental beliefs as a threat to society's 
collective security. According to Duckitt et al., the authoritarians (A subscale) are concerned "about direct physical threats to social and personal safety, well-being and security" (2010). They therefore consider out-groups or social deviants to embody these threats. It is likely that authoritarians do not view people with pro-environmental beliefs as a deviant group. None of the statements in the NEP scale were framed in a particularly disruptive or militant way. Perhaps if the NEP scale had included statements such as "humans have the right to interfere in other people's actions if they are particularly harmful to environment" or something similar, authoritarians would view people who agreed with these as a deviant group that need to be submitted to strong coercive control in order to curb. In the absence of these types of statements, authoritarians may not view those with high pro-environmental beliefs as a clearly deviant group. It is unlikely authoritarians in the current context of the United States would view those with anti-environmental beliefs as a deviant group; the dominant social institutions that apply coercive social control are rooted in the DSP (Shafer, 2006).

The present study found no evidence of a relationship between authoritarian conservatism and pro-environmental beliefs. This is directly at odds with the current understanding of conservatism; theoretically, conservatives should support the DSP as an institution of the status quo. This could be explained by the increasing struggle for dominance between the DSP and the NEP. Conservatives, by definition, are submissive to the dominant social institutions and authorities of society. However, given the social context at the time in which respondents were surveyed, it is possible that events altered the environmental attitudes of some conservative respondents. Dunlap et al. 
notes that new information may change environmental attitudes, which leads to changes in environmental beliefs. Respondents were surveyed during the onset of the COVID-19 crisis in the United States. Two major pieces of information publicized around the time respondents were surveyed may have caused influential changes in some conservatives. Firstly, respondents may have been made aware by media of a variety of reports that highlighted how the environment was benefitting from the COVID-19 lockdown. Publicized environmental changes include examples such as the beach water at a Miami beach appearing visibly clearer and cleaner (Aguirre, 2020), and that people were able to see the Los Angeles skyline in the absence of smog generated by planes and cars (Kann, 2020). Releases about these types of environmental changes in the wake of COVID-19 framed the environmental These may have changed responses to NEP statements such as statement 5- "Humans are severely abusing the environment" and statement 8- "The balance of nature is strong enough to cope with the impacts of modern industrial nations" (Dunlap et al., 2003).

Secondly, just before and during the surveying period, respondents were likely made aware of the suspected origins of the dangerous virus COVID-19: a live animal market in Wuhan, Hubei Province, China (Center for Disease Control, 2020). According to the World Health Organization and the CDC, it most likely was transmitted from an animal to a person, and then from that person to other people (Center for Disease Control 2020; World Health Organization, 2020). Scientists were not able to determine an effective treatment plan, and there was much confusion and disagreement about some response tactics (notably, the efficacy of wearing a non-N95 mask versus not 
wearing one). This may have created insecurity in humanity's collective technical knowledge, impacting how conservatives view nature and, subsequently, how they responded to NEP statements, particularly ones that hint about consequences and humanity's ability to respond to nature's disasters. For instance, NEP statement 3"When humans interfere with nature it often produces disastrous consequences" and NEP statement 9- "Despite our special abilities humans are still subject to the laws of nature" may have been interpreted differently than they would have had respondents been surveyed prior to the outbreak (Dunlap et al., 2003).

It is also possible that conservatives responded to COVID-19 by becoming situationally less conservative. Duckitt and Bizumic have theorized, drawing from a Serbian study in which respondents had excessively low levels of conservatism and had recently gone through a revolution in their country against a restrictive authoritarian regime, that radicalization can take place, reducing levels of conservatism without reducing the scores of other dimensions (2013). The mean C-scale score of the present study is rather low (mean $=-1.51$ ), indicating a low level of conservatism among respondents. It is possible that stricter authoritarian rules as a result of COVID-19 (such as the closing down of many businesses, stay-at-home orders, travel bands, etc.) unlike any laws experienced before caused conservatives to radicalize within the conservative dimension in order to resist rules rather than submit to them.

Finally, it is possible that authoritarians and conservatives are under-represented in the study's respondents, or the composition of the respondents in some way prevented true relationships from emerging. This respondents in the present study were 
not obtained randomly which introduces bias. Future research should determine if these results are replicable. Additionally, future research should investigate the impact of COVID-19 on authoritarianism and environmental beliefs.

\subsection{Environmental Behaviors}

Authoritarianism in the broader meaning has a significant negative relationship with pro-environmental behaviors, and authoritarianism, conservatism, and traditionalism each have a significant negative relationship with pro-environmental behaviors. Establishing a link between norms in the U.S. and the types of behavior the PEB scale focuses on helps to discern possible explanations for the present study's findings. For instance, energy consumption is measured by the PEB. The overconsumption of energy in the United States is considered a social norm, especially when compared to the rest of the world (Nye, 1999). This norm directly stems from the Industrial Revolution, and is rooted deeply in post-industrial society (Nye, 1999). The PEB measures the level of respondents' consumption of meat, as the meat industry contributes substantially to greenhouse gases (Ford, 2011). Food culture in the United States places meat at the center of the average person's diet, indicating the unsustainable, excessive consumption of meat is a norm in the United States (Ford, 2011). Broadly, the norm of transportation across the U.S. is to use a private vehicle, although the use of public transportation has been increasing since about 1990 (Shapiro, Hassett, and Arnold, 2002). The less environmentally friendly actions as measured by PEB can be considered norms in the United States. 
Although the link between environmental beliefs and behaviors is seen as questionable in the literature (Poortinga et al., 2016; Van Riper et al., 2018, Chen et al., 2018; Grob, 1995; Markle, 2013; Lee et al., 2014; Schahn \& Holzer, 2016 found positive relationships; Maloney, Ward \& Braucht, 1975 found no relationship), the present study does find a significantly moderate correlation of 0.43 between environmental beliefs and behaviors. This indicates that there is a relationship between environmental beliefs and behaviors. The DSP, considered the 'norm' that is established by the dominant social institutions and authorities, describes beliefs such as limitless economic growth. If there is a causal relationship between beliefs and behaviors, it stands to reason that a related behavior to limitless growth would be over-consumption of energy and meat, while technological beliefs situated in the DSP may relate to the transportation PEB measures.

Authoritarianism, as one dimension of the larger concept of authoritarianism, may be related due the physicality of behaviors. Potentially, since these behaviors are physical actions and the norms of the collective society, those who are more authoritarian view those who are behaving in more pro-environmental ways as attacking the dominant mode of behavior. While beliefs may not necessarily pose a threat, as this study suggests they do not, it could be that the actions do pose a threat. The threatening aspect may be that if new behaviors are introduced into society, older behaviors may not be 'allowed' in some manner, thus physically threatening the way of life of authoritarians. If the COVID-19 situation influenced responses, it is also possible that COVID-19 could have stimulated authoritarians to become more authoritarian as a 
response to an unprecedented attack on their way of life, whether it was warranted for public health reasons or not. As a result, they may have 'doubled down' on their behaviors.

Traditionalists likely have a negative relationship with environmental behaviors because these behaviors have long been set as tradition. These behaviors exemplify the DSP, as noted above, and the norms of collective society. By participating in these norms, traditionalists uphold their values of traditional lifestyles. 'Modern' behaviors, such as reducing consumption, represent a threat to the traditional lifestyle by introducing possible behavioral alternatives. With these alternatives come, as viewed by traditionalists, confusion and uncertainty about the values of society, particularly the value of the DSP.

These traditional environmentally harmful behaviors are also the status quo of collective society. Conservatives may have a negative relationship with behaviors as less environmentally friendly behaviors are the norm. While beliefs may not be related to conservatism, behaviors are more concrete. If, as theorized above, conservatives are in a state of some confusion regarding the status quo environmental beliefs, they are less likely to be in such a state regarding behavior. Behaviors have been set by tradition and are status quo in most communities across the United States. New behaviors, such as environmentally friendly behaviors, may pose a risk to the cohesiveness of the collective society. New behaviors can cause members of society to behave in a variety of different manners, creating sub-groups of people within the collective society. If these sub-groups are formed, it can fraction the collective society and cause insecurity. 


\section{CONCLUSION}

Overall, this study indicates that a significant negative relationship exists between authoritarianism and pro-environmental beliefs, and a significant negative relationship exists between authoritarianism and pro-environmental behaviors. More specifically, the findings indicate that traditionalism (subscale $\mathrm{T}$ ) is significantly negatively related to pro-environmental beliefs, whereas authoritarianism (subscale A) and conservatism (subscale C) is not significantly related. However, authoritarianism, conservatism, and traditionalism are all significantly related negatively with proenvironmental behaviors. Traditionalists value the traditional beliefs and lifestyles of the collective society; thus, the more traditional one is, the more one values the Dominant Social Paradigm and traditional anti-environmental behaviors. Authoritarians ( $\mathrm{A}$ subscale) value harsh punishments and coercive social control. They perhaps do not view pro-environmental beliefs as a physical attack on society, but this study does indicate that they view pro-environmental behaviors as a physical attack on society. Conservatives value upholding the status quo yet, from the findings, do not appear to significantly identify with pro-environmental beliefs. This seems antithetical, but perhaps there is confusion amongst conservatives concerning beliefs as the dominant 
social institutions of academia and many political authorities publicly clash over the validity of climate change. As respondents become more conservative, however, they do commit behaviors that are more environmentally harmful than less conservative respondents. The disconnect between conservatives' beliefs and behaviors might indicate that, if respondents are becoming situationally less conservative as a response to COVID-19 related events, their behaviors take longer to change than beliefs. It is also possible that, if the lack of a relationship between conservatism and proenvironmental beliefs is due to confusion over conflicting claims from different social institutions, conservatives may be less willing to alter their behaviors to conform with a claim that is disagreed on.

However, the limitations of this study should be considered, especially regarding the implications of the findings. Firstly, the sample size is low $(n=53)$ and was not collected randomly. This may introduce bias, and over- or under-represent certain types of people. Secondly, the relationships found between authoritarianism and proenvironmental beliefs and pro-environmental behaviors should not be interpreted as implying causation. Stronger pro-environmental beliefs and behaviors may influence authoritarianism in a DSP. It is possible in societies that hold the NEP as the established paradigm there may be a positive or absent relationship with authoritarianism. It is also possible authoritarianism causes pro-environmental beliefs and behaviors. Future research should consider investigating this relationship. Thirdly, some items were altered in the PEB scale to better capture behavior without regard for its environmental intent. This may have impacted respondents in an unintentional way. Future research is 
needed to understand how this altered scale may work in other contexts. Additionally, future research would benefit from a scale measuring environmental behaviors solely on the basis of the behavior to gauge how environmentally friendly or unfriendly respondents are regarding only their behavior as opposed to the intent behind their behavior. Fourthly, respondents were surveyed during the onset of the unprecedented COVID-19 crisis. This could have unexpected consequences on authoritarianism, proenvironmental beliefs, and pro-environmental behavior. More research is needed to determine how this crisis has impacted authoritarians, people's endorsements of the NEP, and people's pro-environmental behaviors.

Future research needs to be conducted to understand the link between environmental beliefs and behaviors. Research on authoritarianism should investigate whether people can become situationally more or less conservative and further define the conditions that prompt changes. A better understanding of how conservatives interpret dominant social institutions that exclaim conflicting information (such as political figures proclaiming climate change as fake or an issue that is not pressing while academics and scientists proclaim climate change as an urgent issue) is needed to fully understand conservative motivations and values. Finally, the present study is a pilot study. Therefore, the relationship between pro-environmental beliefs and authoritarianism and the relationship between pro-environmental behaviors and authoritarianism should be retested with college students to determine whether the relationships found hold true. The present researcher plans to use a larger sample size in the future, and will test the dimensionality of the NEP scale, as well as assess 
piecewise regression model fits. These relationships should then be tested in other populations to determine if the relationships are found in the wider population or are specific to college students. 


\section{REFERENCES}

Adorno, T. W., Frenkel-Brunswik, E., Levinson, D. J., \& Sanford, R. N. (1950). The authoritarian personality. New York: Harper \& Row.

Aguirre, L. (2020, April 13). Closed beaches due to coronavirus has South Florida's oceans looking clear and beautiful. WLPG Local 10. Retrieved on May 30, 2020 from https://www.local10.com/news/local/2020/04/13/closed-beacheswaterways-due-to-coronavirus-has-south-floridas-oceans-looking-clear-andbeautiful/

Aichholzer, J. \& Zeglovits, E. (2015). Balanced short scale authoritarian settings (B-RWA6). Compilation of social science items and scales.

Aiello, A., Chirumbolo, A., \& Leone, L. (2004). La Scala di Autoritarismo di Destra (Altemeyer, 1998): Uno studio di adattamento e validazione [Right-wing authoritarianism scale: A study of adaptation and validation to the Italian context]. Rassegna di Psicologia, 21(1), 73-91.

Altemeyer, B. (1981). Right-wing authoritarianism. Winnipeg: University of Manitoba Press. 
Altemeyer, B. (1996). The authoritarian specter. Cambridge, MA: Harvard University Press.

Altemeyer, B. (1998). The other "authoritarian personality." Advances in Experimental Social Psychology, 30(1), 47-92.

Altemeyer, B. (2003). What Happens When Authoritarians Inherit the Earth? A Simulation. Analyses of Social Issues and Public Policy, 3(1).

Altemeyer, B. (2007). The authoritarians. Winnipeg, Canada: University of Manitoba. Retrieved from http://home.cc.umanitoba.ca/ altemey American National Election Studies, University of Michigan, and Stanford University. ANES 2016 Time Series Study. Ann Arbor, MI: Inter-university Consortium for Political and Social Research, 2017-09-19.

Anderson, M. (2012). New Ecological Paradigm (NEP) Scale. Berkshire Encyclopedia of Sustainability, 260-262.

Archer, T. (2007) "Characteristics Associated with Increasing the Response Rates of WebBased Surveys," Practical Assessment, Research, and Evaluation 12(12), p 1-9.

Arcury, T. (1990). Environmental attitude and environmental knowledge. Human Organization, 49(1), 300-304.

Atav, E., Altunoğlu, B. D., \& Sönmez, S. (2015). The Determination of the Environmental Attitudes of Secondary Education Students. Procedia- Social and Behavioral Sciences, 174(1), 1391-1396. 
Bain, P. G., Hornsey, M. J., Bongiorno, R., \& Jeffries, C. (2012). Promoting proenvironmental action in climate change deniers. Nature Climate Change, 2(1), 600-603.

Bizumic, B., \& Duckitt, J. (2018). Investigating Right Wing Authoritarianism with a Very Short Authoritarianism Scale. Journal of Social and Political Psychology, 6(1), 129150.

Camilleri, S. (1959). A Factor Analysis of the F-Scale. Social Forces, 37(4), 316-323.

Center for Disease Control and Prevention. (2020, April 19). Coronavirus disease 2019 situation summary. Retrieved on May 30, 2020 from https://www.cdc.gov/coronavirus/2019-ncov/casesupdates/summary.html\#emergence

Chen, F., Chen, H., Long, R., \& Long, Q. (2018). Prediction of environmental cognition to undesired environmental behavior - the interaction effect of environmental context. Environmental Progress and Sustainable Energy, 37(4), 1361-1370.

Cleopas, A., Kolly, V., \& Perneger, T. (2006). Longer response scales improved the acceptability and performance of the Nottingham Health Profile. Journal of Clinical Epidemiology, 59(11), 1183-1190.

Cohrs, J., \& Asbrock, F. (2009). Right-wing authoritarianism, social dominance orientation and prejudice against threatening and competitive ethnic groups. European Journal of Social Psychology, 39(2), 270-289.

Cribbs, S., \& Austin, M. (2011). Enduring pictures in our heads: The continuance of authoritarianism and racial stereotyping. Journal of Black Studies, 43(3), 334-359. 
Crowson, H. M., \& Brandes, J. A. (2017). Differentiating Between Donald Trump and Hillary Clinton Voters Using Facets of Right-Wing Authoritarianism and SocialDominance Orientation: A Brief Report. Psychological Reports, 120(3), 364-373.

Davis, J. L., Green, J. D., \& Reed, A. (2009). Interdependence with the environment: Commitment, interconnectedness, and environmental behavior. Journal of Environmental Psychology, 29(2), 173-180.

Devine-Wright, P., Price, J., \& Leviston, Z. (2015). My country or my planet? Exploring the influence of multiple place attachments and ideological beliefs upon climate change attitudes and opinions. Global Environmental Change, 30(1).

Duckitt, J.H. (1991). The reliability and validity of Altemeyer's RWA scale in South Africa. Manuscript submitted for publication.

Duckitt, J. (1993). Right-wing authoritarianism among white South African students: Its measurement and correlates. Journal of Social Psychology, 133(1), 553-563.

Duckitt, J. (2009). Authoritarianism and dogmatism. In M. Leary \& R. Hoyle (Eds.), Handbook of individual differences in social behavior (pp. 298-317). New York: Guilford Press.

Duckitt, J. \& Bizumic, B. (2013), Authoritarianism-Conservatism-Traditionalism. Political Psychology, 34(1), 841-862.

Duckitt, J., Bizumic, B., Krauss, S. W., \& Heled, E. (2010). A tripartite approach to rightwing authoritarianism: The authoritarianism-conservatism-traditionalism model. Political Psychology, 31(1), 685-715. 
Duckitt, J., \& Fisher, K. (2003). The impact of social threat on worldview and ideological attitudes. Political Psychology, 24(1) 199-222.

Dunlap, R. E. (2008). The New Environmental Paradigm Scale: From Marginality to Worldwide Use. The Journal of Environmental Education, 40(1), 3-18.

Dunlap, R. E., van Liere, K. D., Mertig, A. G., \& Jones, R. E. (2000). Measuring endorsement of the New Ecological Paradigm: A revised NEP scale. Journal of Social Issues, 56(1), 425-442.

Dunwoody, P. T., \& Funke, F. (2016). The Aggression-Submission-Conventionalism Scale: Testing a New Three Factor Measure of Authoritarianism. Journal of Social and Political Psychology, 4(2), 571-600.

Duriez, B., \& Van Hiel, A. (2002). The march of modern fascism. A comparison of social dominance orientation and authoritarianism. Personality and Individual Differences, 32(7), 1199-1213.

Eckes, T., \& Six, B. (1994). Fakten und Fiktionen in der Einstellungs-Verhaltens-Forschung: Eine Meta-Analyse [Fact and fiction in research on the relationship between attitude and behavior: A meta-analysis]. Zeitschrift für Sozialpsychologie, 25(4), 253-271.

Edwards, Phil \& Roberts, lan \& Sandercock, Peter \& Frost, Chris. (2004). Follow-up by mail in clinical trials: does questionnaire length matter? Controlled Clinical Trials 25(1), 31-52. 
Enzler, H. \& Diekmann, A. (2015). Environmental Impact and Pro-Environmental Behavior: Correlations to Income and Environmental Concern. ETH Zurich Sociology Working Papers, 9.

Eom, K., Kim, H. S., Sherman, D. K., \& Ishii, K. (2016). Cultural Variability in the Link Between Environmental Concern and Support for Environmental Action. Psychological Science, 27(10), 1331-1339.

Ford, B. (2011). Impact of cultured meat on global agriculture. World Agriculture, 2(2), 43-46.

Funke, F. (2005). The dimensionality of right-wing authoritarianism: Lessons from the dilemma between theory and measurement. Political Psychology, 26(2), 195-218.

Giampaglia, G., \& Roccato, M. (2002). La scala di autoritarismo di destra di Altemeyer: Un'analisi con il modello di Rasch per la costruzione di una versione italiana [Altemeyer's right-wing authoritarianism scale: An analysis using Rasch model for the construction of an Italian version]. Testing Psicometria Metodologia, 9(1), 93111.

Gifford, R. (2011). The dragons of inaction: Psychological barriers that limit climate change mitigation and adaptation. The American Psychologist, 66(4), 290-302.

Gifford, R., \& Nilsson, A. (2014). Personal and social factors that influence proenvironmental concern and behaviour: A review. International Journal of Psychology, 49(3), 141-157. 
Gray, D., \& Durrheim, K. (2006). The Validity and Reliability of Measures of Right-Wing Authoritarianism in South Africa. South African Journal of Psychology, 36(3), 500520.

Grob, A. (1995). A structural model of environmental attitudes and behavior. Journal of Environmental Psychology, 15(3), 209-220

Heaven, P. C. (1987). Authoritarianism, dominance, and need for achievement. Australian Journal of Psychology, 39(3), 331-337.

Heaven, P. C. L., \& St. Quintin, D. (2003). Personality factors predict racial prejudice. Personality and Individual Differences, 34(4), 625-634.

Hill, Dawn \& Figueredo, Aurelio \& Jacobs, W. (2013). Contextual influences on sustainable behavior. Psychological Approaches to Sustainability: Current Trends in Theory, Research and Applications. 269-293.

Holmström, S. J. (2015). The Influence of Neuroticism on Proenvironmental Behavior (dissertation). Retrieved from http://urn.kb.se/resolve?urn=urn:nbn:se:oru:diva45446

Jedinger, A. and Burger, A. M. (2019). The role of right-wing authoritarianism and political sophistication in shaping attitudes toward redistribution. European Journal of Social Psychology, 49(3), 560-573

Johnson, C. Y., Bowker, J., \& Cordell, K. (2004). Ethnic Variation in Environmental Belief and Behavior: An Examination of the New Ecological Paradigm in a Social Psychological Context. Environment and Behavior, 36(1), 157-186. 
Joinson, A., Woodley, A., Reips, U. (Jan 2007). Personalization, authentication and selfdisclosure in self-administered Internet surveys. Computers in Human Behavior, 23(1). 275-285.

Kaiser, F. \& Kibbe, A. (2017). Pro-environmental behavior In: Reference module in neuroscience and biobehavioral psychology - [Place of publication not identified]: Elsevier, p. 473-477.

Kaiser, Florian \& Wilson, Mark. (2006). Assessing People's General Ecological Behavior: A Cross-Cultural Measure1. Journal of Applied Social Psychology, 30(1), 952 - 978. Kann, D. (2020, April 7). Los Angeles has notoriously polluted air. But right now it has some of the cleanest of any major city. CNN. Retrieved on May 30, 2020 from https://www.cnn.com/2020/04/07/us/los-angeles-pollution-clean-aircoronavirus-trnd/index.html

Lange, F., \& Dewitte, S. (2019). Measuring pro-environmental behavior: Review and recommendations. Journal of Environmental Psychology, 56(1), 92-100.

Lee, Y., Kim, S., Kim, M., \& Choi, J. (2014). Antecedents and interrelationships of three types of pro-environmental behavior. Journal of Business Research, 67(10), 20972105.

Leiserowitz, A., Maibach, E., Rosenthal, S., Kotcher, J., Bergquist, P., Ballew, M., Goldberg, M., \& Gustafson, A. (2019). Climate Change in the American Mind: November 2019. Yale University and George Mason University. New Haven, CT: Yale Program on Climate Change Communication. 
Little, W. (2012) Introduction to Sociology - 1st Canadian Edition. B.C. Open Textbook project.

Litwak, E. (1956). A Classification of Biased Questions. American Journal of Sociology, $62(2), 182-186$.

Ludeke, S. G., Klitgaard, C. N., \& Vitriol, J. (2018). Comprehensively-measured authoritarianism does predict vote choice: The importance of authoritarianism's facets, ideological sorting, and the particular candidate. Personality and Individual Differences, 123(1), 209-216.

Maas C. (2009). Greenhouse gas and energy co-benefits of water conservation. POLIS Research Report 9(1), 1-33.

Maloney, M., Ward, M., \& Braucht, G. (1975). A revised scale for the measurement of ecological attitudes and knowledge. American Psychologist, 30(7), 787-790.

Marek, P. M., Peterson Jr, A. V., \& Henning, M. (2017). Design and Results for a Survey of Nonrespondents in a Longitudinal Cohort of Young Adults. Journal of Survey Statistics and Methodology, 5(4), 509-534.

Markle, G. (2013). Pro-environmental behavior: Does it matter how it's measured? Development and validation of the Pro-Enviornmental Behavior scale (PEBs). Human Ecology, 41(1), 905-914.

Mavor, K. I., Louis, W. R., \& Sibley, C. G. (2010). A bias-corrected exploratory and confirmatory factor analysis of right-wing authoritarianism: Support for a threefactor structure. Personality and Individual Differences, 48(1), 28-33. 
McDermott, C. (2007). Understanding the psychology of unsustainability: Linking materialism, authoritarianism, attitudes toward gender and the environment, and behavior (PhD thesis). United States: University of Michigan.

Muñoz-Leiva, F., Sánchez-Fernández, J., Montoro-Ríos, F. et al. (2010). Improving the response rate and quality in Web-based surveys through the personalization and frequency of reminder mailings. Quality \& Quantity, 44(5), 1037-1052.

Naderi, I. (2018). I'm Nice, Therefore I Go Green: An Investigation of Proenvironmentalism in Communal Narcissists. Journal of Environmental Psychology, 59(1), 54-64.

Olli, E., Grendstad, G., \& Wollebaek, D. (2001). Correlates of environmental behaviors Bringing back social context. Environment and Behavior, 33(2), 181-208.

Osborne, J. W. \& Costello, A. B. (2004). Sample size and subject to item ratio in principal components analysis. Practical Assessment, Research, and Evaluation, 9(11), 1-9.

Pagiaslis, A., \& Krontalis, A. (2014). Green consumption behavior antecedents: Environmental concern, knowledge, and beliefs. Psychology \& Marketing, 31(5), $335-348$.

Peterson, B. E., Doty, R. M., \& Winter, D. G. (1993). Authoritarianism and attitudes toward contemporary social issues. Personality and Social Psychology Bulletin, 19(2), 174-184.

Poortinga, W., Steg, L., \& Vlek, C. (2016). Values, Environmental Concern, and Environmental Behavior. Environment and Behavior, 36(1), 70-93. 
Prati, G., Albanesi, C., \& Pietrantoni, L. (2017) The interplay among environmental attitudes, pro-environmental behavior, social identity, and pro-environmental institutional climate. A longitudinal study. Environmental Education Research, 23(2), 176-191.

Pratto, F., Sidanius, J., Stallworth, L., \& Malle, B. (1994). Social dominance orientation: A personality variable predicting social and political attitudes. Journal of Personality and Social Psychology, 67(1) 741-763.

Rattazzi, A., Bobbio, A., \& Canova, L. (2007). A short version of the Right-Wing Authoritarianism (RWA) Scale. Personality and Individual Differences, 43(1), $1223-1234$

Ray, J. J. (1985). Defective validity in the Altemeyer authoritarianism scale. The Journal of Social Psychology, 125(2), 271-272.

Reese, G. (2012). When Authoritarians Protect the Earth-Authoritarian Submission and Proenvironmental Beliefs: A Pilot Study in Germany. Ecopsychology, 4(3), 232-236 Robb, K. A., Gatting, L., Wardle, J. (2017). What impact do questionnaire length and monetary incentives have on mailed health psychology survey response? British Journal of Health Psychology, 22(4), 671-685.

Rubinstein, G. (1995). Authoritarianism in Israeli society. The Journal of Social Psychology, 135(2), 237-249.

Rubinstein, G. (1996). Two Peoples in One Land: A Validation Study of Altemeyer's RightWing Authoritarianism Scale in the Palestinian and Jewish Societies in Israel. Journal of Cross-Cultural Psychology, 27(2), 216-230. 
Saleh, A. Bista, K. (2017). Examining Factors Impacting Online Survey Response Rates in Educational Research: Perceptions of Graduate Students. Journal of MultiDisciplinary Evaluation, 13(29), 63-74.

Schahn, J., \& Holzer, E. (2016). Studies of Individual Environmental Concern. Environment and Behavior, 22(6), 767-786.

Schirmer, J. (May 2009). Ethical Issues in the Use of Multiple Survey Reminders. Journal of Academic Ethics 7(1), 125-139.

Schultz, W. P., \& Stone, W. F. (1994). Authoritarianism and attitudes toward the environment. Environment and Behavior, 26(1), 25-37.

Shafer, W.E. (2006). Social paradigms and attitudes toward environmental accountability. Journal of Business Ethics, 65(2), 121-147.

Shapiro, R.J., Hassett, K.A., \& Arnold, F.S. (2002). Conserving Energy and Preserving the Environment: The Role of Public Transportation.

Sinn, J. S. and Hayes, M. W. (2018), Is Political Conservatism Adaptive? Reinterpreting Right-Wing Authoritarianism and Social Dominance Orientation as Evolved, Sociofunctional Strategies. Political Psychology, 39(5), 1123-1139.

Sirakaya-Turk, E., Uysal, M., Hammitt, W. E., \& Vaske, J. J. (2017). Research Methods for Leisure, Recreation and Tourism, 2nd Edition. CABI.

Stanley, Samantha \& Wilson, Marc. (2018). Meta-analysing the association between social dominance orientation, authoritarianism, and attitudes on the environment and climate change. Journal of Environmental Psychology, 61(1), 4656. 
Stolzmann, K., Meterko, M., Miller, C.J., Belanger, L., Seibert, M.N., \& Bauer, M.S. (2018). Survey Response Rate and Quality in a Mental Health Clinic Population: Results from a Randomized Survey Comparison. The Journal of Behavioral Health Services \& Research, 46(1), 521-532.

Taber, K.S. (2018). The Use of Cronbach's Alpha When Developing and Reporting Research Instruments in Science Education. Research in Science Education, 48(1), $1273-1296$.

Van Mol, C. (2017) Improving web survey efficiency: the impact of an extra reminder and reminder content on web survey response. International Journal of Social Research Methodology, 20(4), 317-327

Van Riper, C. J., Lum, C., Kyle, G. T., Wallen, K. E., Absher, J., \& Landon, A. C. (2018). Values, Motivations, and Intentions to Engage in Proenvironmental Behavior. Environment and Behavior, 00(0), 1-26.

Vesely, S., Brick, C., \& Klöckner, C.A. (2019, in press). Pro-environmental behavior as a signal of cooperativeness: Evidence from a social dilemma experiment. Journal of Environmental Psychology.

Voas, D. (2013). Towards a Sociology of Attitudes. Sociological Research Online, 19(1). http://www.socresonline.org.uk/19/1/12.html

Walton, T. \& Austin, M. (2011). Pro-environmental behavior in an urban social structural context. Sociological Spectrum, 31(1), 260-287.

World Health Organization. (2020, April 23). Coronavirus disease 2019 (COVID-19) situation report - 94. Retrieved on May 30, 2020 from 
https://www.who.int/docs/default-source/coronaviruse/situationreports/20200423-sitrep-94-covid-19.pdf

Xiao, C., Dunlap, R., \& Hong, D. (2019) Ecological Worldview as the Central Component of Environmental Concern: Clarifying the Role of the NEP. Society \& Natural Resources, 32(1), 53-72.

Zakrisson, I. (2005). Construction of a short version of the right-wing authoritarianism (RWA) scale. Personality and Individual Differences, 39(1), 863-872.

Zelezny, L., Chua, P., \& Aldrich, C. (2000). Elaborating on gender differences in environmentalism. Journal of Social Issues, 56(3), 443-457.

Ziegler, A. (2017). Political orientation, environmental values, and climate change beliefs and attitudes: An empirical cross country analysis. Energy Economics, 63(1), 144153. 


\section{APPENDIX A}

\section{Survey Instrument}

The following questions will ask you about specific habits. Please choose the most appropriate response.

1. How often do you turn off the lights when leaving a room?

Never

Rarely

Sometimes

Usually

Always

2. How often do you switch off standby modes of appliances or electronic devices?

3. How often do you cut down on heating or air conditioning?

4. How often do you turn off the TV when leaving a room?

5. How often do you wait until you have a full load to use the washing machine or dishwasher?

6. At which temperature do you wash most of your clothes?

Hot

Warm

Cold 
A mixed-temperature cycle

7. How many minutes do you typically spend showering?

5 minutes or less

6 - 10 minutes

$11-15$ minutes

16 - 20 minutes

21 minutes or more

Page break

8. Are you currently a member of any environmental, conservation, or wildlife protection group, including recognized student organizations?

No

Yes

9. During the past year have you contributed money to an environmental, conservation, or wildlife protection group, including recognized student organizations?

10. How often do you watch television programs, movies, or internet videos about environmental issues?

Never

Rarely

Sometimes

Often

Constantly 
11. How often do you talk to others about their environmental behavior?

$$
\text { Page break }
$$

12. In a typical week, how frequently do you eat organically grown fruits and vegetables?

Not at all

Once per week

A few times per week

Once a day

More than once per day

13. In a typical week, how frequently do you eat beef?

14. In a typical week, how frequently do you eat pork?

15. In a typical week, how frequently do you eat poultry?

Page break

16. Please answer the following question based on the vehicle you drive most often:

on average, how many miles per gallon does the vehicle get?

24 or less mpg

$25-29 \mathrm{mpg}$

$30-34 \mathrm{mpg}$

$35-39 \mathrm{mpg}$

40 or more mpg

I do not drive any vehicles

17. During the past year how frequently have you car-pooled? 
Never

Occasionally

Frequently

18. During the past year how frequently have you used public transportation?

19. During the past year how frequently have you walked or cycled instead of driving?

Page break

Please indicate how much you disagree or agree with each of the following statements.

20. We are approaching the limit of the number of people the earth can support.

Strongly disagree

Mildly disagree

Unsure

Mildly agree

Strongly agree

21. Humans have the right to modify the natural environment to suit their needs.

22. When humans interfere with nature it often produces disastrous consequences.

23. Human ingenuity will ensure that we do NOT make the earth unlivable.

24. Humans are severely abusing the environment.

25. The earth has plenty of natural resources if we just learn how to develop them.

26. Plants and animals have as much right as humans to exist. 
27. The balance of nature is strong enough to cope with the impacts of modern industrial nations.

$$
\text { Page break }
$$

Please indicate how much you disagree or agree with each of the following statements.

28. Despite our special abilities, humans are still subject to the laws of nature.

29. The so-called "ecological crisis" facing humankind has been greatly exaggerated.

30. The earth is like a spaceship with very limited room and resources.

31. Humans were meant to rule over the rest of nature.

32. The balance of nature is very delicate and easily upset.

33. Humans will eventually learn enough about how nature works to be able to control it.

34. If things continue on their present course, we will soon experience a major ecological catastrophe.

\section{Page break}

Please indicate how much you disagree or agree with each of the following statements.

35. It's great that many young people today are prepared to defy authority. Very strongly disagree

Strongly disagree

Somewhat disagree

Slightly disagree 
Unsure

Slightly agree

Somewhat agree

Strongly agree

Very strongly agree

36. What our country needs most is discipline, with everyone following our leaders in unity.

37. Students at high schools and at universities must be encouraged to challenge, criticize, and confront established authorities.

38. Obedience and respect for authority are the most important virtues children should learn.

39. Our country will be great if we show respect for authority and obey our leaders.

40. People should be ready to protest against and challenge laws they don't agree with.

\section{Page break}

41. Nobody should stick to the "straight and narrow." Instead people should break loose and try out lots of different ideas and experiences.

42. The "old-fashioned ways" and "old-fashioned values" still show the best way to live.

43. God's laws about abortion, pornography, and marriage must be strictly followed before it is too late.

44. There is absolutely nothing wrong with nudist camps. 
45. This country will flourish if young people stop experimenting with drugs, alcohol, and sex, and pay more attention to family values.

46. There is nothing wrong with premarital sexual intercourse.

Page break

47. Strong, tough government will harm, not help, our country.

48. Being kind to loafers or criminals will only encourage them to take advantage of your weakness, so it's best to use a firm, tough hand when dealing with them.

49. Our society does NOT need tougher government and stricter laws.

50. The facts on crime and the recent public disorders show we have to crack down harder on troublemakers if we are going preserve law and order.

51. Our prisons are a shocking disgrace. Criminals are unfortunate people who deserve much better care, instead of so much punishment.

52. The way things are going in this country, it's going to take a lot of "strong medicine" to straighten out the troublemakers, criminals, and perverts.

The following questions will ask you about your feelings and experiences related to safety on [redacted] campus. Please choose the most appropriate response.

53. How safe do you feel on campus at nighttime?

Not safe at all

Somewhat unsafe

Somewhat safe

Very safe 
Since attending [redacted], while you were on campus have you...

54. Carried your keys in your hand in a defensive manner?

Never

Sometimes

Frequently

Always

55. Asked someone to walk with you to your destination after dark for safety purposes?

56. Avoided specific areas of campus at night because you were afraid of being robbed, assaulted, or threatened?

57. Have you or anyone you know ever been attacked, mugged, or robbed while out walking on campus?

No

Yes

\section{Page break}

Please choose the most appropriate response.

58. What is your current age?

59. Please choose the gender you most closely identify with.

Male

Female 
Trans male

Trans female

Nonbinary

Another gender not listed here

60. Please indicate your ethnicity.

Hispanic

Non-Hispanic

61. Please indicate your racial identity. Choose all that apply.

White

Black or African American

American Indian or Alaska Native

Asian

Another race not listed here

62. What year are you classified as?

First-year student

Sophomore

Junior

Senior

Graduate student

63. Please enter your major (separate multiple majors with commas).

64. What was your total household income last year before taxes? 
Less than $\$ 24,999$

$\$ 25,000-\$ 29,999$

$\$ 30,000-\$ 39,999$

$\$ 40,000-\$ 49,999$

$\$ 50,000-\$ 59,999$

$\$ 60,000-\$ 69,999$

$\$ 70,000-\$ 79,999$

$\$ 80,000$ and above

Unsure

65. Which most closely matches your political views?

Extremely conservative

Conservative

Slightly conservative

Moderate

Slightly liberal

Liberal

Extremely liberal

66. Please enter your cumulative GPA at the end of the $2018-2019$ academic year. High school GPAs are acceptable.

My GPA is... (please enter)

I do not have a GPA

67. During the academic year, which best describes your living situation? 


\section{Campus dormitories}

Fraternity or Sorority housing

Campus-affiliated apartments

Off-campus residency

We thank you for your time spent taking this survey.

Your response has been recorded. 


\section{Communications}

Initial Email

Subject: Request for Participation in Research Study

Hello $\$\{m: / / F i r s t N a m e\}$,

My name is Rebecca Halpryn, and I am an M.A. student at the University of Louisville. I am emailing you to invite you to participate in a confidential $10-15$-minute online survey for a research study entitled "Authoritarianism, Fear of Crime, and ProEnvironmental Beliefs and Behaviors Amongst College Students". This research is the basis of my M.A. thesis, which is necessary for me to graduate, and is being conducted under the guidance of Dr. Mark Austin. You are receiving this email because you [redacted].

Your opinions and experiences are valuable! To take the survey, please click on the following link:

\section{$\$\{1: / /$ SurveyLink?d=Take the Survey $\}$}

Or copy and paste this in your browser: $\$\{1: / /$ SurveyURL $\}$

This link is active until date. After date, the survey will be closed, and we will no longer accept responses. Please do not share this link with anyone.

Eligibility: You are eligible to complete this survey if you are 18 years of age or older. 
You are eligible to complete this survey if you are [redacted].

Benefits: There are no known direct benefits to you for completing the survey.

Risks and Harms: There are no known risks to completing this survey. There are no known harms from completing this survey. This is an IRB-approved research study.

Purpose: The information you provide will help the researchers understand possible connections between environmental beliefs and behaviors, authoritarianism, and fear of crime. Your completed survey will be stored online.

For more information or to contact the researchers, please contact [redacted].

Thank you for your time, Rebecca Halpryn

[redacted], University of Louisville

First Reminder Email

Subject: Request for Participation in Research Study 
Hello $\$\{m: / / F i r s t N a m e\}$,

My name is Rebecca Halpryn, and I am an M.A. student at the University of Louisville. I am emailing you to remind you that you have been invited to participate in a 10-15minute online survey for a research study entitled "Authoritarianism, Fear of Crime, and Pro-Environmental Beliefs and Behaviors Amongst College Students". This research is the basis of my M.A. thesis, which is necessary for me to graduate, and is being conducted under the guidance of Dr. Mark Austin. You are receiving this email because you [redacted].

Your opinions and experiences are valuable! To take the survey, please click on the following link:

\section{$\$\{1: / /$ SurveyLink?d=Take the Survey\}}

Or copy and paste this in your browser: $\{\{1: / /$ SurveyURL $\}$

This link is active until date. After date, the survey will be closed, and we will no longer accept responses. Please do not share this link with anyone.

Eligibility: You are eligible to complete this survey if you are 18 years of age or older. You are eligible to complete this survey if you are [redacted].

Benefits: There are no known direct benefits to you for completing the survey. 
Risks and Harms: There are no known risks to completing this survey. There are no known harms from completing this survey. This is an IRB-approved research study.

Purpose: The information you provide will help the researchers understand possible connections between environmental beliefs and behaviors, authoritarianism, and fear of crime. Your completed survey will be stored online.

For more information or to contact the researchers, please contact [redacted].

Thank you for your time,

Rebecca Halpryn

[redacted], University of Louisville

Second Reminder Email

Subject: Request for Participation in Research Study

Hello $\$$ m://FirstName\},

My name is Rebecca Halpryn, and I am an M.A. student at the University of Louisville. I am emailing you to remind you that you have been invited to participate in a 10-15minute online survey for a research study entitled "Authoritarianism, Fear of Crime, and Pro-Environmental Beliefs and Behaviors Amongst College Students". This research is 
the basis of my M.A. thesis, which is necessary for me to graduate, and is being conducted under the guidance of Dr. Mark Austin. You are receiving this email because you have not yet completed the survey. This is the final reminder I will send you.

Your opinions and experiences are valuable! To take the survey, please click on the following link:

\section{$\$\{1: / /$ SurveyLink?d=Take the Survey\}}

Or copy and paste this in your browser: $\$\{1: / /$ SurveyURL $\}$

This link is active until date. After date, the survey will be closed, and we will no longer accept responses. Please do not share this link with anyone.

Eligibility: You are eligible to complete this survey if you are 18 years of age or older.

You are eligible to complete this survey if you are [redacted].

Benefits: There are no known direct benefits to you for completing the survey.

Risks and Harms: There are no known risks to completing this survey. There are no known harms from completing this survey. This is an IRB-approved research study.

Purpose: The information you provide will help the researchers understand possible connections between environmental beliefs and behaviors, authoritarianism, and fear of 
crime. Your completed survey will be stored online.

For more information or to contact the researchers, please contact [redacted].

Thank you for your time,

Rebecca Halpryn

[redacted], University of Louisville 


\title{
CURRICULUM VITA
}

\author{
NAME: $\quad$ Rebecca Halpryn \\ EDUCATION: B.A., Sociology \\ Berea College \\ 2014-2018 \\ M.A., Sociology \\ University of Louisville \\ 2018-2020 \\ HONORS AND University Fellowship \\ AWARDS: $\quad$ University of Louisville, Louisville \\ 2018 \\ PUBLICATIONS: Heberle, L., Kinahan, K., Rohret, D., Wheeler J., \& Halpryn, R. \\ (2019). State of Metropolitan Housing Report: 22,000 Equities, \\ Addressing Racial Gaps in Homeownership and Wealth. University \\ of Louisville's Center for Environmental Policy and Management.
}

DOI: 10.13140/RG.2.2.10824.88320. 